\title{
Corticosterone and dopamine D2/D3 receptors mediate the motivation for voluntary wheel running in $\mathrm{C} 57 \mathrm{BL} / 6 \mathrm{~J}$ mice
}

\author{
Mohamed Elsaed Ebada ${ }^{1,2} \mathrm{PhD}$, David A Kendall ${ }^{1} \mathrm{PhD}$, Marie-Christine Pardon* ${ }^{1}$ \\ $\mathrm{PhD}$
}

University of Nottingham Medical School, School of Life Sciences, ${ }^{1}$ Neuroscience group, Queen's Medical Centre, Nottingham, NG7 2UH, United Kingdom;

${ }^{2}$ Present address: Pharmacology Department, National Organization for Drug Control and Research (NODCAR), Dokki, Cairo, Egypt

*Corresponding Author: $\quad$ Marie-Christine Pardon, $\mathrm{PhD}$

\author{
School of Life Sciences \\ Neuroscience group, \\ University of Nottingham Medical School \\ Queen's Medical Centre \\ Nottingham, NG7 2UH, United Kingdom
}

$\mathrm{Ph}:$ +44 1158230149

FAX: +44 1158230142

email: marie.pardon@nottingham.ac.uk

$\underline{\text { Running title: Corticosterone, dopamine and voluntary wheel running }}$

Number of figures: 5

Number of tables: 1

Number of words in the abstract: $\mathbf{2 4 8}$

Number of words in the manuscript (including tables and figure legends): 6,639

Number of words in the introduction: $\mathbf{1 , 2 9 0}$

Number of words in the discussion: $\mathbf{1 , 2 4 3}$ 


\begin{abstract}
Physical exercise can improve cognition but whether this is related to motivation levels is unknown. Voluntary wheel running is a rewarding activity proposed as a model of motivation to exercise. To question the potential effects of exercise motivation on subsequent behaviour, we used a pharmacological approach targeting some reward mechanisms. The stress hormone corticosterone has rewarding effects mediated by activation of low affinity glucocorticoid receptors (GR). To investigate whether corticosterone synthesis motivates exercise via activation of GRs and subsequently, impacts on behaviour, we treated C57BL/6J mice acutely with the inhibitor of corticosterone synthesis metyrapone $(35 \mathrm{mg} / \mathrm{kg})$ or repeatedly with the GR antagonist mifepristone $(30 \mathrm{mg} / \mathrm{kg}$ ) prior to 1 -hour running wheel sessions. To investigate whether reducing motivation to exercise impacts on behaviour, we antagonised running-induced dopamine D2/D3 receptors activation with sulpiride (25 or $50 \mathrm{mg} / \mathrm{kg}$ ) and assessed locomotor, anxiety-related and memory performance after 20 running sessions over 4 weeks. We found that corticosterone synthesis contributes to running levels, but the maintenance of running behaviour was not mediated by activation of GRs. Intermittent exercise was not associated with changes in behavioural or cognitive performance. The persistent reduction in exercise levels triggered by sulpiride also had limited impact on behavioural performance, although the level of performance for some behaviours was related to the level of exercise. Altogether, these findings indicate that corticosterone and dopamine D2/D3 receptor activation contribute to the motivation for wheel running, but suggest that motivation for exercise is not a sufficient factor to alter behaviour in healthy mice.
\end{abstract}

Keywords: Corticosterone; voluntary wheel running; dopamine D2/D3 receptors; glucocorticoid receptors; memory; C57BL/6J mice 


\section{Introduction}

The benefits of an active lifestyle for physical and mental health are widely accepted. In both animals and humans, physical exercise improves cognitive function across the lifespan and slows down the progression of cognitive disorders such as Alzheimer's disease [1], but the underlying mechanisms are not fully understood. Encouraging people to exercise is, therefore, a promising strategy to promote health but the level of participation is related to motivation factors such as interest/enjoyment and competence which were also found to be related to positive mental health outcomes [2]. It is however unknown whether motivational aspects of exercise, rather than the exercise level per se, contribute to the cognitive and behavioural effects.

Voluntary wheel running has been proposed as a preclinical model of exercise motivation rather than of general locomotor activity based on a large body of evidence supporting the hypothesis that rodents engage in wheel running because it has positive salience for them (for review see [3, 4]). Wheel running was indeed found to be reinforcing and rewarding and to activate brain rewards pathways. For instance, rats lever-press for an opportunity to run [5], develop conditioned place preference to the context associated with running $[3,5]$ and show a rebound response to forced abstinence [3]. Furthermore, the effects of voluntary wheel running on the brain mimic those of other natural rewards and drugs of abuse [6, 7]. Thus, the level of exercise during voluntary wheel running is an indicator of motivation to exercise. The effects of voluntary exercise on the brain and behaviour also differ from those of forced exercise even when the form and level of exercise are controlled. Forced exercise is routinely induced using a treadmill. The direct comparisons of treadmill and voluntary wheel running showed that both procedures improved spatial memory, but forced exercise also recruited fear-related neural pathways and increased aversive memory [8]. The fact that treadmill running may be seen as a different form of exercise than wheel running could contribute to the differential effects. However, by comparing forced and voluntary wheel running, it was shown that both procedures increased behavioural and neurochemical indices of reward, which appeared elicited by distinct mechanisms possibly differentiating the motivation to exercise from its rewarding effects [9]. Furthermore, similar levels of forced and voluntary wheel running were found associated with an increase in hippocampal neurogenesis that was greater in the forced exercise group who also showed increased anxiogenic-like behaviour [10]. Thus, altogether these data suggest that the motivation to exercise can exert effects on brain and behaviour that are independent of exercise levels.

The work reported here examined some mechanisms underlying the motivation for exercise using voluntary wheel running as a model and questioned the relationship between motivational aspects of exercise and its behavioural effects. Forced exercise has a stressful component that may contribute to its effects on the brain [11]. Although less stressful than forced exercise [11], voluntary wheel running also activates the hypothalamic pituitary adrenocortical (HPA) axis and elevates plasma levels of the stress hormone corticosterone [12, 13]. Interestingly, corticosterone, 
when induced or administered at sufficient levels, has direct reinforcing and rewarding properties and enhances reinforcing and rewarding effects of abused drugs via activation of the low affinity glucocorticoid receptor (GR) [14-18]. This raises the question of whether corticosterone levels induced by voluntary exercise contribute to the motivation for exercise or are induced as a consequence of exercise. The first goal of this study was therefore to test the hypothesis that corticosterone mediates the motivation to exercise. This was addressed by treating C57BL/6J mice acutely with metyrapone, an inhibitor of corticosterone synthesis, prior to being allowed access to a 1-hour running wheel sessions. Additionally, corticosterone release was found to contribute to the improvement in memory induced by voluntary exercise [19]. The second goal of this study was therefore to test the hypothesis that corticosterone provokes the motivation to exercise via activation of GR receptors and, as such, impacts on behaviour. This was addressed by treating C57BL/6J mice repeatedly with the GR antagonist mifepristone prior to being allowed access to 1-hour running wheel sessions. An intermittent exercise regimen was chosen as the findings can be more translated to human who exercise intermittently than unlimited access to running wheel. Behavioural performance was assessed in locomotor, anxiety-related and memory tests.

The final goal of this study was to investigate whether reducing the motivation for wheel running, impacts on behaviour. Motivation for exercise has been linked to dopaminergic reward pathways. The rewarding effects of voluntary wheel running have been found to be associated with neuroplastic changes in the mesolimbic pathway, that include downregulation of dopaminergic D2 receptor mRNA expression in the nucleus accumbens core of rats [20]. Preference for voluntary exercise over sucrose was also found reduced after treatment with the D2 antagonist haloperidol [21]. Furthermore, the D2 antagonist raclopride reduced voluntary wheel running in mice [22] suggesting that sustained stimulation of D2 receptors contributes to the motivation for exercise. In addition, the motivation for wheel running was found reduced by inactivation of the nucleus accumbens [3], a brain region where D3 receptors, which are less abundant than D2 receptors, are preferentially expressed [23]. Thus, to reduce motivation for wheel running, we used a pharmacological approach targeting exercise-induced activation of dopamine D2/D3 receptors with the antagonist sulpiride [24]. Although dopamine receptors are involved both in locomotor and motivated behaviours, sulpiride was found to be more effective on dopamine receptors located in the mesolimbic reward pathway than in the nigrostriatal dopamine pathways [25] and devoid of effects on spontaneous motor activity [26]. It is, therefore, a suitable drug to block motivation for exercise.

To investigate whether motivation levels are related to the behavioural effects of exercise, we tested the association between exercise levels and Our main findings were that corticosterone synthesis and activation of D2/D3 receptors during voluntary wheel running contribute to exercise levels but had a limited impact on subsequent behavioural performance, suggesting that motivation for exercise is not a sufficient factor to alter behaviour in healthy mice. 


\section{Materials and Methods}

\subsection{Animals}

6-8-week-old male C57BL/6J mice were obtained from Charles River UK, individually caged and left to acclimatize for 1 week. Standard environmental conditions and 12:12 light/dark cycle (lights on at 7:00 am) were applied in the animal holding room throughout all experiments. Mice had ad libitum access to food and water and their body weight was recorded weekly. All procedures undertaken in these studies were in accordance with the UK Animal Scientific Procedures Act 1986 under project licence 40/3283. Data are reported according to the ARRIVE guidelines for in vivo experiments [27]

\subsection{Drug treatment}

Metyrapone (corticosterone synthesis inhibitor), mifepristone (RU38486, GR antagonist) and $( \pm$ )-sulpiride (D2/D3 receptor antagonist) were purchased from Sigma-Aldrich UK. Metyrapone (35 mg/kg, i.p.) was dissolved in saline. Mifepristone (30 mg/kg, i.p.) was suspended in vehicle A, $1 \%$ Tween 80 in saline, and sonicated for 30 seconds on ice. ( \pm )-sulpiride ( 25 or $50 \mathrm{mg} / \mathrm{kg}$, i.p.) was freshly dissolved in vehicle $\mathrm{B}$ (1\% acetic acid/saline) and the solution was adjusted to $\mathrm{pH} 7$ with $1 \mathrm{M}$ $\mathrm{NaOH}$.

\subsection{Running wheels}

Each wheel $(11.5 \mathrm{~cm}$ in diameter) was tightly fixed to the internal side of the cage lid. A cycle computer was attached to the side of the cage lid and its sensor directed at a distance of $<1 \mathrm{~cm}$ towards a magnet piece mounted on the wheel to count the number of the revolutions. Cycle computers were calibrated to automatically calculate the running distances over exercise sessions.

\subsection{Spontaneous alternation in a T-maze.}

The apparatus consisted of three arms of equal dimensions (41.5 cm long, 6 $\mathrm{cm}$ wide in grey Plexiglas surrounded by $15 \mathrm{~cm}$ high walls in transparent Plexiglas) as described previously [28]. After 1-minute of habituation, mice underwent 9 consecutive trials. Each mouse was placed in the starting box $(7.5 \mathrm{~cm}$ long $)$ at the beginning of the central path for 5 seconds, and once the animal entered an arm, the doors to both arms were closed for 15 seconds. The mouse was then allowed to return to the starting box. The test was repeated twice and the data averaged. The percentage of correct alternations was calculated and the criterion for successful spatial working memory performance was an alternation rate significantly above chance level (50\%).

\subsection{Novel object recognition and location tests.}


A Perspex arena $(30 \times 35 \times 25 \mathrm{~cm})$ with transparent sides and a grey floor was used. The behaviour was recorded by a camera positioned directly above the arena and subsequently analysed using Ethovision Software (Noldus, Wageningen, Netherlands). Two sets of objects were used, triangular and circular wooden blocks or octogonal and rectangular wooden red and white blocks, counterbalanced between mice to avoid preference bias.

Mice were first individually habituated to the empty open-field arena for 30 minutes, during which their distance travelled was automatically recorded and the percentage of activity occurring in the centre of the arena (defined as a $21 \times 8 \mathrm{~cm}$ area) was also calculated to ensure that any differences in object exploration levels between treatment groups were due to differences in memory and not activity and/or anxiety levels.

Twenty-four hours later, each mouse was subjected to the two trials of the object recognition test. Mice were first allowed to explore a single object for 10 minutes and 4 hours later, they could freely explore two objects, the familiar object from the acquisition trial and a novel object (different shape) for a further 10 minutes, as described previously [29].

Twenty-four hours later, mice were subjected to the two 10-minute trials of the object location test, separated by 1 hour. Each mouse was first left to explore two identical objects. The location of one object was changed during a second trial to another corner of the arena, so that the two objects were diametrically opposed.

Object exploration, defined as the animal's nose pointing towards the object at a distance $\leq 0.5 \mathrm{~cm}$, was assessed by eye, scored twice by an observer blind to the experimental groupings and averaged for each animal. If the two values differed by more than $10 \%$, a third scoring was performed and the two closest values were used for statistical analyses.

The apparatus and objects were cleaned with $20 \%$ ethanol between tests to remove olfactory cues.

\subsection{Plasma corticosterone levels}

Total corticosterone levels were determined using enzyme-linked immunoassays (ADI-900-097, Enzo Life, USA) according to the manufacturer's instructions. The sensitivity of the assay was $27 \mathrm{pg} / \mathrm{ml}$ : the intra-assay and inter-assay coefficients of variation were $7.7 \%$ and $9.7 \%$, respectively. All samples were run in duplicate. The plate was read at $405 \mathrm{~nm}$ and correction made at $580 \mathrm{~nm}$ using SoftMax® Pro V 4.0 (Life Sciences Edition).

\subsection{Statistical analysis}

Data are presented as mean \pm SEM and were analysed using InVivoStat [30] as described below, with the exception of one-sample t-tests which were performed using SPSS (SAS Institute, Inc. V16.0) to compare the percentage of correct 
alternation, recognition and location indexes to chance level (50\%). Details of the statistical tests used for each experiment are described below. Correlations between exercise levels and corticosterone or behavioural variables were also calculated using the Pearson correlation coefficient. Our statistically significant correlation coefficients were generally not very high as the data is generally restricted in range but can be considered stables since our sample size exceeded 20. An effect was considered significant when $\mathrm{p}$ values were $\leq 0.05$ and post-hoc planned comparisons were used where appropriate.

\subsection{Study design}

The first experiment investigated the development of voluntary wheel running during repeated 1-hour sessions and whether it was associated with behavioural and cognitive effects and corticosterone synthesis (Fig. 1A). Mice that fail to engage in running wheel behaviour $(\mathrm{n}=3$ ) were excluded from the study, as it is known that some mice do not develop consistent running behaviour [4]. Mice were first assessed for spatial working memory performance in the spontaneous alternation test (Day 0) and then assigned to either the running or sedentary groups $(n=10)$. They then underwent a series of daily 1-hour running sessions or exposure to a static wheel (5 days/week) for 5 weeks. After the completion of the exercise regimen, mice's memory was evaluated in the spontaneous alternation (Day 38), open-field (Day 39), novel object recognition and location tests (Days 40 and 41, respectively). On Day 45, the mice were subjected to an additional running session immediately before being sacrificed for collection of trunk blood. One-way ANOVA with repeated measures over weeks was used to analyse the development and maintenance of running behaviour. Two-way ANOVAs with group as the between subject factor and repeated measures over time or trials were performed on the spontaneous alternation rate, total exploration times during the object memory tests and body weight data. Unpaired ttests were used to compare sedentary and running mice for anxiety-related behaviour in the open field, recognition and location indexes in the object tests, as well as running distances and plasma corticosterone levels during the final running session.

Because intermittent wheel running had little effect on behaviour but induced corticosterone synthesis, we then assessed whether corticosterone plays a role in running performance (Fig. 2A). The first experiment indicated that running behaviour developed gradually and that some mice failed to exhibit it. Therefore, training was induced to ensure a sufficient level of exercise on the challenge day to accurately assess the impact of metyrapone. 32 mice were trained for wheel-running by being offered up to ten 1-hour running sessions. Training ended when mice were motivated to run over 2-3 consecutive sessions reaching an average performance of about 0.3 $\mathrm{km} /$ hour during the last 2 training sessions. Data from the first experiment indicated that this criterion was associated with sustained performance. Running mice were then subjected to a final running session the next day, 30 minutes after being administered intraperitoneally (i.p.) with saline (Running-Saline group, $\mathrm{n}=9$ ) or with the inhibitor of corticosterone synthesis metyrapone $(35 \mathrm{mg} / \mathrm{kg}$ as in [31], Running-Metyrapone 
group, $\mathrm{n}=11$ ). Two mice were excluded as they did not access the wheel following the injection. The saline-treated sedentary group (Sedentary-Saline, $\mathrm{n}=11$ ) included mice which failed to reach the criteria of $0.3 \mathrm{~km} /$ hour for 2 successive days which was offered a static wheel during the final session for the determination of non-exercising plasma corticosterone levels. Immediately afterwards, mice were sacrificed by cervical dislocation and trunk blood collected for determination of plasma corticosterone levels. The impact of metyrapone on voluntary wheel running was assessed by comparing the average performance of running mice over the last 2 training days to that of the final session using a one-way ANOVA with treatment as the between subject factor and repeated measures over running sessions. One-way ANOVA, with group as the between subject factor, was used to analyse plasma corticosterone levels at the end of the final session.

Corticosterone synthesis contributed to voluntary wheel running performance; therefore, in the third experiment (Fig. 3C), we investigated whether the effect of corticosterone on exercise levels was mediated by the GR receptors using the GR antagonist mifepristone. We also investigated whether reducing motivation to run would impact on behaviour by antagonising exercise-induced dopamine D2/D3 receptors activation with sulpiride. After acclimatization, all mice were subjected to a 2-week training phase as described above (1-hour/day, 5 days/week) to ensure that potential drugs' effects were not due to a lack of motivation to run. Baseline spatial alternations performance was evaluated on Day 11. Mice were then assigned to the sedentary (exposed to static wheels) and running groups, and further subdivided into 4 subgroups $(\mathrm{n}=8-9)$ administered i.p. with vehicle $(\mathrm{A}, \mathrm{n}=4-5$ and $\mathrm{B}, \mathrm{n}=4)$, the GR antagonist mifepristone in vehicle $\mathrm{A}(30 \mathrm{mg} / \mathrm{kg})$, or the D2/D3 antagonist sulpiride at doses of 25 or $50 \mathrm{mg} / \mathrm{kg}$ (sulpiride 25 and sulpiride 50) in vehicle B. These doses were found to be effective for 1-hour-long interventions [15, 32-34]. Sulpiride and mifepristone were administered 30 minutes and 2 hours before each running session, respectively. Mice were then assessed in the spontaneous alternation (Day 42), openfield (Day 43), novel object recognition and object location tests (Days 44 and 45 respectively). On Day 49, mice were killed immediately after their final running session by cervical dislocation. Trunk blood was collected and plasma was kept at $80^{\circ} \mathrm{C}$ for the determination of plasma corticosterone levels. The effect of drug treatment on running distances was analysed using two-way ANOVAs with exercise (running $v s$ sedentary) and treatment (vehicle, mifepristone, sulpiride 25 and sulpiride 50) as between subject factors and repeated measure over time. Two-way ANOVAs were used to analyse corticosterone levels, distance moved and anxiety-related behaviour in the open field, recognition and location indexes, with exercise and treatment as between subject factors. Three-way ANOVAs with repeated measures were used to analyse the percentage of correct alternations, body weight, and total exploration times during the object tests. Exercise and treatment were the between subject factors, and alternation testing times (before and after treatment), body weight recording times (weekly for 8 weeks) or trials (training and testing) were the within subjects factors. Post-hoc planned comparisons were performed when appropriate, and $\mathrm{p}<0.05$ was considered statistically significant. 


\subsection{Additional control groups}

To control for the impact of environmental enrichment (wheel exploration) on behavioural measures, a vehicle-treated, no-wheel group was assessed alongside ( $\mathrm{n}=$ 8). Because we have previously found that repeated injections affect memory performance in C57bl/6 mice [35], and to assess whether it also altered running levels, a separate non-injected group was also included $(n=8)$. The effects of injection or static wheel exposure were assessed by comparing performance with vehicletreated mice using one way ANOVAs with repeated measure ANOVA for running distances and unpaired t-tests for all other variables. The data are presented as supplementary information.

\section{Results}

Main statistical effects for each experimental variable are reported in Table 1.

\section{PLEASE INSERT TABLE 1 ABOUT HERE}

\subsection{Exercise-induced rise in corticosterone levels was not associated with behavioural or cognitive effects.}

Running behaviour developed gradually over the 5 weeks $[\mathrm{F}(4,36)=52.59$, p $<0.0001]$. During the first 3 weeks, distance travelled increased significantly from 0.143 to $0.73 \mathrm{~km}$ ( $\mathrm{p}<0.05$ for week 2 compared to both week 1 and week 3 ) but it plateaued around $0.8 \mathrm{~km} /$ hour thereafter (Fig. 1B). On the final session, corticosterone levels of running mice were significantly higher than those of sedentary mice offered a static wheel $[\mathrm{t}(18)=6.03, \mathrm{p}<0.0001$, Fig. 1C]. Sedentary and running mice did not differ significantly in relation to body weight gain, locomotor, anxiety-related and memory performance (Suppl. Table 1).

\section{PLEASE INSERT FIGURE 1 ABOUT HERE}

\subsection{Corticosterone synthesis contributes to voluntary wheel running}

To clarify the role of corticosterone synthesis in voluntary wheel running, mice were acutely pre-treated with metyrapone. During the last two training sessions, mice ran an average of $0.5 \mathrm{~km}$ per hour (Fig. 2A). Running distances were attenuated by about $33 \%$ after metyrapone pre-treatment on the challenge day [Treatment $\mathrm{X}$ running sessions: $\mathrm{F}(1,18)=12.01, p=0.003$; post-hoc tests: $\mathrm{p}<0.05$ compared to both training levels and Running-Saline on the final session, Fig. 2B]. The exerciseinduced rise in plasma corticosterone levels ( $p<0.05$ compared to Sedentary-Saline) was also prevented by metyrapone ( $p<0.05$ compared to Running-Saline, Fig. $2 \mathrm{C}$; 
exercise $X$ treatment : $F(2,28)=4.86, p=0.01)$ and running distances of exercising mice were positively associated with their plasma levels of corticosterone $[n=20, r=$ $0.39, \mathrm{p}=0.04$, Fig. 1D]. Thus, motivation to run is, in part, supported by corticosterone synthesis.

\section{PLEASE INSERT FIGURE 2 ABOUT HERE}

\subsection{Antagonism of running-induced GR activation transiently attenuated voluntary wheel running performance}

All experimental groups achieved a similar level of exercise at the end of the 2-week training phase, running about $0.7 \mathrm{~km} /$ per hour (Fig. 3B). Running distances were not affected by daily injections (Suppl. Table 2) and remained stable in the vehicle-treated mice throughout the 4 weeks of the treatment phase (Fig. 3B). Mifepristone transiently and moderately attenuated running behaviour, decreasing it during the first week of treatment ( $\mathrm{p}<0.05$ compared to training, Fig. 3B), particularly on the first and third day, ( $\mathrm{p}<0.05$ compared to training, Suppl. Fig. 1A) with full recovery to training levels from week 2 ( $\mathrm{p}<0.05$ for week 2,3 and 4 compared to week 1, Fig. 3B). In contrast, sulpiride persistently decreased running activity throughout the study in a dose-dependent manner. Pre-treatment with the 25 $\mathrm{mg} / \mathrm{kg}$ dose decreased running distances by about $25 \%$ ( $\mathrm{p}<0.05$ compared to training for most sessions, Suppl. Fig. 1A and Fig. 3B) while the $50 \mathrm{mg} / \mathrm{kg}$ dose reduced performance by $70 \%$ ( $p<0.0001$ compared to training for all the sessions over the 4 weeks Suppl. Fig. 1A and Fig. 3B). On the final running session, 7 days later, mice pre-treated with $50 \mathrm{mg} / \mathrm{kg}$ of sulpiride ran significantly less than the other 3 treatment groups $(p<0.05$ in all cases, Fig. 3C). Exercise increased corticosterone levels in vehicle- $(p<0.0001)$ and mifepristone-treated mice $(p=0.05)$, but not in sulpiridetreated mice who had significantly lower hormone levels at the end of the running session than those of vehicle-treated running mice ( $p<0.05$ in both cases, Fig. 3D). Corticosterone levels, which were not affected by the stress of injection or environmental enrichment (Suppl. Table 2) were positively associated with running distances $[n=33, r=0.42, p=0.003$, Fig. 3E].

\section{PLEASE INSERT FIGURE 3 ABOUT HERE}

\subsection{Intermittent wheel-running does not impact behavioural performance}

In vehicle-treated mice, no effect of exercise was found on spatial alternation rate (Fig. 4A and Suppl. Table 3), distance moved (Fig. 5A) and anxiety-related behaviour (Fig. 5A and Suppl. Table 3) in the open field, object exploration times in the object recognition (Fig. 5D) and location (Fig. 5F) tests, or object and spatial discrimination (Figs. 4B and 4C). This lack of behavioural effects is consistent with the results of the first experiment (Suppl. Table 1) and unlikely to be confounded by environmental enrichment or the stress of injection which had limited behavioural 
impact (Suppl. Table 2). Indeed, access to a static wheel significantly increased exploration times in both trials of the object recognition tests $[F(1,14)=20.43, p<$ 0.001], without affecting object recognition memory, whereas spatial discrimination of the two additional control groups, not offered a static wheel or not subjected to the repeated injections, was slightly improved as their location index were significantly above chance level (Suppl. Table 2).

\subsection{Mifepristone lowered memory performance regardless of exercise}

The improvement in spontaneous alternation performance seen with repeated testing was not observed in mifepristone-treated mice (Fig. 4A and Suppl. Table 3) which, regardless of exercise, also showed reduced object recognition $(p=0.03$ compared to vehicle-treated mice; Fig. 4B) while still discriminating the novel object above chance levels ( $p<0.05$ compared to $50 \%$ in both cases, Fig. 4B). Open-field behaviour (Fig. 5A and Suppl. Table 3), object exploration times (Fig. 5B and 5C) and spatial discrimination (Fig. 4C) were not altered by antagonism of GRs regardless of exercise.

\subsection{Sulpiride had complex dose- and exercise-dependent behavioural effects}

In the spontaneous alternation test, sulpiride enhanced performance of running mice at a dose of $25 \mathrm{mg} / \mathrm{kg}$ ( $\mathrm{p}=0.008$ compared to 0 ) and of sedentary mice at a dose of $50 \mathrm{mg} / \mathrm{kg}$ ( $p=0.02$ compared to 0 ) by about $20 \%$ (Fig. 4B). The $25 \mathrm{mg} / \mathrm{kg}$ dose reduced ambulatory activity in the open-field regardless of exercise ( $p=0.008$ compared to vehicle-treated mice; Fig. 5A), but the $50 \mathrm{mg} / \mathrm{kg}$ dose had no significant locomotor effect (Fig. 5A). Regardless of the dose, sulpiride enhanced object exploration in the acquisition of the object recognition test, particularly in exercising mice $(25 \mathrm{mg} / \mathrm{kg}: p=0.002,50 \mathrm{mg} / \mathrm{kg}: \mathrm{p}<0.0001$ compared to vehicle-treated running mice; Fig. 5D). The increased object investigation was also seen in the retention trial for sulpiride 50 regardless of exercise (acquisition: $p=0.005$, retention: $p=0.003$ compared to vehicle-treated; Suppl. Table 3) and was associated with reduced object recognition ( $\mathrm{p}=0.03$ compared to vehicle-treated mice; Fig. 4B). In contrast, the performance of sedentary mice treated with $25 \mathrm{mg} / \mathrm{kg}$ of sulpiride was not altered, although antagonism of exercise-induced D2/D3 activation impaired object recognition performance $(\mathrm{p}=0.01$ compared to vehicle-treated running mice and $\mathrm{p}=$ 0.005 compared to sulpiride 25-treated sedentary mice; Fig. 4B). All groups, however, discriminated the novel object above chance levels. Similarly, in the object location tests, regardless of the dose, sulpiride enhanced object exploration in the acquisition trial, particularly in exercising mice $(25 \mathrm{mg} / \mathrm{kg}: \mathrm{p}=0.009,50 \mathrm{mg} / \mathrm{kg}: \mathrm{p}=0.003$ compared to sulpiride-treated running mice; Fig. 5B) without significantly altering the discrimination of spatial location (Fig. 5C). In summary, the most significant effect of sulpiride was to increase inquisitive behaviour, particularly in running mice, but it was without major effects on memory performance. 


\section{PLEASE INSERT FIGURE 4 and FIGURE 5 ABOUT HERE}

\subsection{Behavioural performance is relatively independent of the level of exercise}

Correlations between the cumulative distance run over the 4 weeks of treatment and each behavioural variable indicate weak positive associations between the level of exercise and spatial discrimination in the object location test $[\mathrm{n}=35, \mathrm{r}=$ $0.31, p=0.04$, Fig. 4D], the number of faecal pellets in the open-field $[n=35, r=$ $0.29, p=0.04$, Fig. 5C] and object exploration times during the acquisition trial of the object recognition test $[n=35, r=0.55, p=0.0006$, Fig. 5D]. This would suggest that the mice more motivated to run are better at spatial discrimination and more curious whilst also being more emotional.

\section{Discussion}

This series of experiments questioned the relationship between motivational aspects of exercise and its behavioural effects. We first tested the hypothesis that corticosterone contributes to motivation for exercise and as such impacts on behaviour and investigated whether reducing motivation for voluntary wheel running would alter behavioural performance in in locomotor, anxiety-related and memory tests. Our main finding is that corticosterone synthesis contributes to running performance in mice offered intermittent access to 1-hour running wheel sessions, but the maintenance of running behaviour does not appear to be mediated by activation of GRs. The exercise-induced corticosterone secretion persisted after 25 sessions, but was not associated with changes in behavioural and cognitive performance suggesting that motivation to exercise is not sufficient to alter behaviour. Consistent with this hypothesis, the persistent reduction in running wheel activity caused by antagonism of dopaminergic D2/D3 receptors also had limited impact on behavioural performance. Thus, both corticosterone synthesis and activation of dopamine D2/D3 receptors contributed to the motivation for exercise but the level of engagement in wheel running had limited impact on behavioural performance.

\subsection{Intermittent voluntary wheel running does not alter behavioural and cognitive performance}

Unlimited access to voluntary wheel running generally improves memory in C57BL/6J mice [36, 37]. The lack of behavioural and cognitive effects of intermittent wheel running in our study raises the question of whether there are optimal levels of exercise for behavioural changes to occur. Indeed, a study in rats found that behavioural effects of exercise were dependent on the task and exercise level with low intensity runners showing improved object recognition memory and high intensity runners being impaired, however, increased anxiogenic-like reactions were observed regardless of the exercise level [38]. In contrast, our correlation data would suggest that the mice keener on running are better at spatial discrimination and are less 
curious whilst also being more emotional. The source of this discrepancy could be the specie or related to exercise levels as we applied an intermittent exercise regimen while the study reported provided unlimited access to wheel running [38]. The timing of exercise can also be a significant factor. Although mice are nocturnal and, when given unlimited access to a running wheel, they preferentially exercise during the night, running distances were only found to be affected during the light phase when access to exercise was given for more than 1 hour [39]. However, C57BL/6J mice had to run for at least 3 hours at night to demonstrate a significant increase in hippocampal neurogenesis [39], a mechanism thought to mediate the cognitionenhancing effects of exercise [37, 40]. It is therefore possible that the behavioural impact of intermittent exercise would be greater if it was applied during the dark phase of the cycle.

Other methodological factors could contribute to the lack of behavioural effects of exercise and were controlled for here. First, we found previously that the repeated stress of injection impairs memory in C57BL/6J mice [35], but it had no impact on running activity and behavioural effects of exercise in the present study. Novelty and environmental enrichment can also contribute to the positive effects of exercise [41] but this was not the case here. We showed previously that repeated exposure to a novel environment, which also induces physical exercise, improved memory in a mouse model of Alzheimer's disease but not in wild-type C57BL/6J mice $[35,42,43]$ while exposure to a static wheel was sufficient to improve some cognitive measures in another Alzheimer's mouse model [44]. Altogether, this suggests that the enrichment aspect of exercise may only beneficial to cognitive performance in animals with pre-existing memory impairments.

\subsection{Corticosterone synthesis motivates voluntary wheel running}

Voluntary wheel running-induced corticosterone secretion was positively associated with running distances during the final exercise session as well as total distance run throughout the experiment (Suppl. Fig. 1B), ruling out habituation of the HPA axis to the repeated exercise. This is in agreement with previous work in mice selectively bred for high engagement in voluntary wheel running, showing that the acute corticosterone response to exercise is unaffected by repeated voluntary exercise [45]. The positive correlation between running distances and corticosterone secretion raised the question of whether corticosterone levels are a cause or a consequence of running behaviour. While the elevation in corticosterone levels resulting from forced exercise [46] would indicate that it results from the stress of running, we found that metyrapone significantly decreased the running distances of trained mice after a single session. Both inhibition of corticosterone synthesis with metyrapone and adrenalectomy were previously found to moderately reduce running distances of rats offered unlimited access to running wheels [19]. This indicates that corticosterone regulates the motivation to run but is not necessary for the acquisition and maintenance of running behaviour. One possibility is that it exerts reinforcing effects once a certain level of exercise and/or corticosterone is achieved. GRs, which are 
activated by stress levels of the hormone, are important for rewarding and reinforcing effects of abused drugs in animals $[14,15]$ and are thought to mediate the rewarding effects of corticosterone [47]. The moderate and short-lasting effects of mifepristone on voluntary running activity suggest that motivating effects may possibly be initiated via a GR-dependent mechanism, but not their persistence. This is in agreement with the observation that GR levels were found to be unaltered by 4 weeks of voluntary wheel running, despite a downregulation of the high affinity mineralocorticoid receptors [13] which may thus contribute more to motivation to exercise than GRs.

Corticosterone plays a critical role in cognitive performance [48], can prevent memory impairments [17] and corticosterone secretion was found to mediate the improvement in memory induced by voluntary exercise [19]. We, however, found that mifepristone had only weak effects on memory performance independent of exercise, also suggesting that GRs do not mediate the cognitive effects of exercise.

\subsection{Reducing motivation for exercise has limited behavioural impact}

Dopamine has been suggested to influence learning and memory especially when a motivated behaviour is involved [49]. The repeated treatment with sulpiride had no impact on cognitive performance in the absence of exercise, and only reduced spontaneous alternation performance after exercise at the lowest dose. However, antagonism of exercise-induced D2/D3 receptors activation significantly increased object investigation in the object recognition and location tasks, suggesting a persistent increase in inquisitive behaviour. Chronic sulpiride treatment was found to up-regulate dopamine D3 receptor levels without affecting D1 and D2 levels [50]. This may be interpreted as a compensatory mechanism responding to the blockade of D3 receptors, which is potentially cognition-enhancing [51]. However, long term blockade of D2 receptors can lead to increased dopamine release and the activation of other dopamine receptors [52]. Thee higher availability of D3 receptors would thus be consistent with the observation that stimulation of D3 receptors impairs performance in the novel object test [53]. Furthermore, stimulation of D4 receptors was found to stimulate object exploration [54] as was observed in sulpiride-treated mice.

\section{Conclusions}

This study has demonstrated that enhanced corticosterone synthesis mediates voluntary wheel running, albeit to a lesser extent than dopamine D2/D3 receptor activation, and as such contribute to the motivation for exercise. GRs activation, however, was not required for mice to sustain running activity. The exercise regimen used here failed to improve memory, although we found that performance of some behaviours was related to exercise level. Thus, under certain circumstances, motivation for exercise may contribute to its behavioural effects. Further studies are, however, needed to address whether this is only true in the case of pre-existing cognitive impairments. 


\section{Table and figure legends.}

Figure 1. Corticosterone response to exercise induced by voluntary wheel running A) Timeline of the experiment. Mice were offered access to a running or static wheel for 1 hour 5 times a week for 5 weeks after baseline assessment of spontaneous alternation performance. They were assessed for locomotor activity, anxiety-related behavior, spatial and recognition memory after the exercise regimen and offered a final running session the following week for determination of exerciseinduced corticosterone levels. B) Mean \pm SE weekly distance ran (km). Running activity developed gradually over the first 3 weeks and then plateaued at about 0.8 $\mathrm{km} /$ hour. $* * * \mathrm{p}<0.0001$ and $* * \mathrm{p}<0.01$ compared to previous week. C) Mean $\pm \mathrm{SE}$ plasma corticosterone levels $(\mathrm{ng} / \mathrm{ml})$ increased with exercise. $* * * p<0.0001$ compared to exposure to a static wheel.

Figure 2. Corticosterone synthesis mediates voluntary wheel running. A) Timeline of the experiment. Trained mice were offered access to a running or static wheel for 1 hour, 30 minutes after administration of the corticosterone synthesis inhibitor metyrapone $(35 \mathrm{mg} / \mathrm{kg}$, i.p.) or its vehicle (saline). They were culled immediately after for determination of exercise-induced corticosterone in plasma. B) Mean \pm SE distance $(\mathrm{km})$ ran during the last 2 training sessions and on the drug challenge day. Inhibition of corticosterone synthesis significantly decreases running activity. ${ }^{*} \mathrm{p}<0.01$ compared to training levels and $* \mathrm{p}<0.05$ compared to salinetreated mice. C) Mean \pm SE plasma corticosterone levels $(\mathrm{ng} / \mathrm{ml})$ after exercise. Metyrapone prevented exercise-induced corticosterone levels. **p $<0.01$ and $* \mathrm{p}<$ 0.05 compared to saline-treated running mice. D) Plasma corticosterone levels during the final running session were positively associated with exercise levels.

Figure 3. Activation of dopamine D2/D3 receptors mediates voluntary wheel running. A) Timeline of the experiment. In trained mice, after baseline assessment of spontaneous alternation performance, the glucocorticoid receptor (GRs) antagonist mifepristone $(30 \mathrm{mg} / \mathrm{kg}$ i.p.) and the D2/D3 antagonist (25 or $50 \mathrm{mg} / \mathrm{kg}$ i.p.) were administered prior to each running session to determine the extent to which their activation during exercise contributes to running activity. Mice were assessed for locomotor activity, anxiety-related behavior, spatial and recognition on week 7 and offered a final running session the following week to determine whether blockade of GR and D2/D3 receptors also impact on exercise-induced corticosterone levels. B) Mean \pm SE weekly distance ran $(\mathrm{km})$. Antagonism of exercised-induced GR activation attenuates running levels during the first week of treatment while antagonism of D2/D3 receptor activation dose-dependently reduces running distances. $* * * \mathrm{p}<0.0001, * * \mathrm{p}<0.01$ and $* \mathrm{p}<0.05$ compared to pre-treatment levels. C) Mean \pm SE distance $(\mathrm{km})$ ran during the final exercise session. $* * p<0.01$ and $* \mathrm{p}<0.05$ compared to saline-treated running mice. D) Mean \pm SE plasma corticosterone levels (ng/ml) after exercise. Antagonism of D2/D3 receptors prevented exercise-induced corticosterone levels. $* * * p<0.0001, * * p<0.01$ and $* p<0.05$. E) Plasma 
corticosterone levels during the final running session were positively associated with exercise levels.

Figure 4. Exercise levels have limited impact on spatial and recognition memory. A) Mean \pm SE change in spontaneous alternation rate (\%) after blockade of exercise induced glucocorticoid receptor (GRs) activation with mifepristone $(30 \mathrm{mg} / \mathrm{kg}$ i.p. $)$ and dopamine D2/D3 receptor activation with sulpiride (25 or $50 \mathrm{mg} / \mathrm{kg}$ i.p.). B) Mean \pm SE preference $(\%)$ for the novel object in the test phase of the object recognition test. While all mice significantly discriminated the novel object $\left({ }^{\# \#} \mathrm{p}<\right.$ $0.0001,{ }^{\#} \mathrm{p}<0.01$ and ${ }^{\#} \mathrm{p}<0.05$ compared to chance levels), mifepristone and the higher dose of sulpiride $(50 \mathrm{mg} / \mathrm{kg}$, i.p.) significantly reduced performance. At the 25 $\mathrm{mg} / \mathrm{kg}$ dose, blockade of exercised-induced D2/D3 activation also reduced recognition memory. ${ }^{* *} \mathrm{p}<0.0001,{ }^{*} \mathrm{p}<0.01$ and $* \mathrm{p}<0.05$. C) Mean \pm SE preference $(\%)$ for the object at the novel location. There was no significant effect of either treatment regardless of exercise. D) Levels of discrimination of spatial location were positively associated with exercise levels throughout the treatment phase.

Figure 5. Exercise levels are related to emotionality and curiosity. A) Mean \pm SE distance moved (metres) in a 30 minutes open-field session. Ambulatory activity is reduced in mice treated with $25 \mathrm{mg} / \mathrm{kg}$ of sulpiride, regardless of exercise. B) Mean \pm SE number of faecal pellets in the open-field. C) The number of faecal pellets was positively associated with exercise levels throughout the treatment phase. D) Mean \pm SE time (seconds) spent exploring the objects during the acquisition of the object recognition test. Blockade of D2/D3 receptors during exercise increased object investigation, compared to vehicle-treated running mice. E) Exploration times during the acquisition trial of the object recognition test were negatively associated with exercise levels throughout the treatment phase. F) Mean \pm SE time (seconds) spent exploring the objects during the acquisition of the object location test. Antagonism of D2/D3 receptors during exercise increased object investigation. $* * p<0.01$ and $* \mathrm{p}<$ 0.05 .

Table 1. Results of the ANOVAs performed on each experimental variable.

\section{Acknowledgments.}

ME Ebada's PhD scholarship was generously supported by the Egyptian Ministry of Higher Education. 


\section{References}

[1] Mattson MP. Lifelong brain health is a lifelong challenge: From evolutionary principles to empirical evidence. Ageing Res Rev. 2015;20:37-45.

[2] Frederick CM, Ryan RM. Differences in motivation for sport and exercise and their relations with participation and mental health. Journal of Sport Behavior 1993;16:124-46.

[3] Basso JC, Morrell JI. The medial prefrontal cortex and nucleus accumbens mediate the motivation for voluntary wheel running in the rat. Behavioral neuroscience. 2015;129:457-72.

[4] Novak CM, Burghardt PR, Levine JA. The use of a running wheel to measure activity in rodents: relationship to energy balance, general activity, and reward. Neuroscience and biobehavioral reviews. 2012;36:1001-14.

[5] Belke TW, Wagner JP. The reinforcing property and the rewarding aftereffect of wheel running in rats: a combination of two paradigms. Behavioural processes. 2005;68:165-72.

[6] Olsen CM. Natural rewards, neuroplasticity, and non-drug addictions. Neuropharmacology. 2011;61:1109-22.

[7] Brene S, Bjornebekk A, Aberg E, Mathe AA, Olson L, Werme M. Running is rewarding and antidepressive. Physiol Behav. 2007;92:136-40.

[8] Liu YF, Chen HI, Wu CL, Kuo YM, Yu L, Huang AM, et al. Differential effects of treadmill running and wheel running on spatial or aversive learning and memory: roles of amygdalar brain-derived neurotrophic factor and synaptotagmin I. The Journal of physiology. 2009;587:3221-31.

[9] Herrera JJ, Fedynska S, Ghasem PR, Wieman T, Clark PJ, Gray N, et al. Neurochemical and behavioral indices of exercise reward are independent of exercise controllability. The European journal of neuroscience. 2016.

[10] Leasure JL, Jones M. Forced and Voluntary Exercise Differentially Affect Brain and Behavior. Neuroscience. 2008;156:456-65.

[11] Hayes K, Sprague S, Guo M, Davis W, Friedman A, Kumar A, et al. Forced, not voluntary, exercise effectively induces neuroprotection in stroke. Acta neuropathologica. 2008;115:289-96.

[12] Adlard PA, Cotman CW. Voluntary exercise protects against stress-induced decreases in brain-derived neurotrophic factor protein expression. Neuroscience. 2004; 124:985-92.

[13] Droste SK, Gesing A, Ulbricht S, Muller MB, Linthorst AC, Reul JM. Effects of long-term voluntary exercise on the mouse hypothalamic-pituitary-adrenocortical axis. Endocrinology. 2003;144:3012-23.

[14] Dong Z, Han H, Wang M, Xu L, Hao W, Cao J. Morphine conditioned place preference depends on glucocorticoid receptors in both hippocampus and nucleus accumbens. Hippocampus. 2006;16:809-13.

[15] Fiancette JF, Balado E, Piazza PV, Deroche-Gamonet V. Mifepristone and spironolactone differently alter cocaine intravenous self-administration and cocaineinduced locomotion in C57BL/6J mice. Addiction biology. 2010;15:81-7.

[16] Deroche V, Marinelli M, Le Moal M, Piazza PV. Glucocorticoids and behavioral effects of psychostimulants. II: cocaine intravenous self-administration and reinstatement depend on glucocorticoid levels. J Pharmacol Exp Ther. 1997;281:1401-7.

[17] Ebada ME, Latif LM, Kendall DA, Pardon MC. Corticosterone protects against memory impairments and reduced hippocampal BDNF levels induced by a chronic 
low dose of ethanol in C57BL/6J mice. Romanian journal of morphology and embryology $=$ Revue roumaine de morphologie et embryologie. 2014;55:1303-16.

[18] Deroche V, Piazza PV, Deminiere JM, Le Moal M, Simon H. Rats orally selfadminister corticosterone. Brain research. 1993;622:315-20.

[19] Hajisoltani R, Rashidy-Pour A, Vafaei AA, Ghaderdoost B, Bandegi AR, Motamedi F. The glucocorticoid system is required for the voluntary exercise-induced enhancement of learning and memory in rats. Behavioural brain research. 2011;219:75-81.

[20] Greenwood BN, Foley TE, Le TV, Strong PV, Loughridge AB, Day HE, et al. Long-term voluntary wheel running is rewarding and produces plasticity in the mesolimbic reward pathway. Behavioural brain research. 2011;217:354-62.

[21] Correa M, Pardo M, Bayarri P, Lopez-Cruz L, San Miguel N, Valverde O, et al. Choosing voluntary exercise over sucrose consumption depends upon dopamine transmission: effects of haloperidol in wild type and adenosine AKO mice. Psychopharmacology. 2015.

[22] Rhodes JS, Garland T. Differential sensitivity to acute administration of Ritalin, apomorphine, SCH 23390, but not raclopride in mice selectively bred for hyperactive wheel-running behavior. Psychopharmacology. 2003;167:242-50.

[23] Gardner EL, Ashby CR, Jr. Heterogeneity of the mesotelencephalic dopamine fibers: physiology and pharmacology. Neuroscience and biobehavioral reviews. 2000;24:115-8.

[24] Vallone D, Picetti R, Borrelli E. Structure and function of dopamine receptors. Neuroscience and biobehavioral reviews. 2000;24:125-32.

[25] White FJ, Wang RY. Differential effects of classical and atypical antipsychotic drugs on A9 and A10 dopamine neurons. Science. 1983;221:1054-7.

[26] Manzanedo C, Aguilar MA, Minarro J. The effects of dopamine D2 and D3 antagonists on spontaneous motor activity and morphine-induced hyperactivity in male mice. Psychopharmacology. 1999;143:82-8.

[27] Kilkenny C, Browne WJ, Cuthill IC, Emerson M, Altman DG. Improving bioscience research reporting: the ARRIVE guidelines for reporting animal research. PLoS biology. 2010;8:e1000412.

[28] Pardon MC, Kendall DA, Perez-Diaz F, Duxon MS, Marsden CA. Repeated sensory contact with aggressive mice rapidly leads to an anticipatory increase in core body temperature and physical activity that precedes the onset of aversive responding. The European journal of neuroscience. 2004;20:1033-50.

[29] Scullion GA, Kendall DA, Marsden CA, Sunter D, Pardon MC. Chronic treatment with the alpha2-adrenoceptor antagonist fluparoxan prevents age-related deficits in spatial working memory in APPxPS1 transgenic mice without altering beta-amyloid plaque load or astrocytosis. Neuropharmacology. 2011;60:223-34.

[30] Clark RA, Shoaib M, Hewitt KN, Stanford SC, Bate ST. A comparison of InVivoStat with other statistical software packages for analysis of data generated from animal experiments. J Psychopharmacol. 2012;26:1136-42.

[31] Chauveau F, Tronche C, Pierard C, Liscia P, Drouet I, Coutan M, et al. Rapid stress-induced corticosterone rise in the hippocampus reverses serial memory retrieval pattern. Hippocampus. 2010;20:196-207.

[32] Le Merrer J, Stephens DN. Food-induced behavioral sensitization, its crosssensitization to cocaine and morphine, pharmacological blockade, and effect on food intake. The Journal of neuroscience : the official journal of the Society for Neuroscience. 2006;26:7163-71. 
[33] Le Merrer J, Gavello-Baudy S, Galey D, Cazala P. Morphine self-administration into the lateral septum depends on dopaminergic mechanisms: Evidence from pharmacology and Fos neuroimaging. Behavioural brain research. 2007;180:203-17.

[34] Gavello-Baudy S, Le Merrer J, Decorte L, David V, Cazala P. Selfadministration of the GABAA agonist muscimol into the medial septum: dependence on dopaminergic mechanisms. Psychopharmacology. 2008;201:219-28.

[35] Scullion GA, Hewitt KN, Pardon MC. Corticotropin-releasing factor receptor 1 activation during exposure to novelty stress protects against Alzheimer's disease-like cognitive decline in AbetaPP/PS1 mice. Journal of Alzheimer's disease : JAD. 2013;34:781-93.

[36] Berchtold NC, Castello N, Cotman CW. Exercise and time-dependent benefits to learning and memory. Neuroscience. 2010;167:588-97.

[37] Clark PJ, Brzezinska WJ, Thomas MW, Ryzhenko NA, Toshkov SA, Rhodes JS. Intact neurogenesis is required for benefits of exercise on spatial memory but not motor performance or contextual fear conditioning in C57BL/6J mice. Neuroscience. 2008;155:1048-58.

[38] Garcia-Capdevila S, Portell-Cortes I, Torras-Garcia M, Coll-Andreu M, CostaMiserachs D. Effects of long-term voluntary exercise on learning and memory processes: dependency of the task and level of exercise. Behavioural brain research. 2009;202:162-70.

[39] Holmes MM, Galea LA, Mistlberger RE, Kempermann G. Adult hippocampal neurogenesis and voluntary running activity: circadian and dose-dependent effects. J Neurosci Res. 2004;76:216-22.

[40] Speisman RB, Kumar A, Rani A, Foster TC, Ormerod BK. Daily exercise improves memory, stimulates hippocampal neurogenesis and modulates immune and neuroimmune cytokines in aging rats. Brain, behavior, and immunity. 2013;28:25-43.

[41] Hatchard T, Ting JJ, Messier C. Translating the impact of exercise on cognition: methodological issues in animal research. Behavioural brain research. 2014;273:17788.

[42] Rattray I, Pitiot A, Lowe J, Auer DP, Lima SJ, Schubert MI, et al. Novel cage stress alters remote contextual fear extinction and regional T2 magnetic resonance relaxation times in TASTPM mice overexpressing amyloid. Journal of Alzheimer's disease : JAD. 2010;20:1049-68.

[43] Rattray I, Scullion GA, Soulby A, Kendall DA, Pardon MC. The occurrence of a deficit in contextual fear extinction in adult amyloid-over-expressing TASTPM mice is independent of the strength of conditioning but can be prevented by mild novel cage stress. Behavioural brain research. 2009;200:83-90.

[44] Nichol KE, Parachikova AI, Cotman CW. Three weeks of running wheel exposure improves cognitive performance in the aged $\operatorname{Tg} 2576$ mouse. Behavioural brain research. 2007;184:124-32.

[45] Girard I, Garland T, Jr. Plasma corticosterone response to acute and chronic voluntary exercise in female house mice. J Appl Physiol. 2002;92:1553-61.

[46] Chang YT, Chen YC, Wu CW, Yu L, Chen HI, Jen CJ, et al. Glucocorticoid signaling and exercise-induced downregulation of the mineralocorticoid receptor in the induction of adult mouse dentate neurogenesis by treadmill running. Psychoneuroendocrinology. 2008;33:1173-82.

[47] Piazza PV, Deroche V, Deminiere JM, Maccari S, Le Moal M, Simon H. Corticosterone in the range of stress-induced levels possesses reinforcing properties: implications for sensation-seeking behaviors. Proc Natl Acad Sci U S A. 1993;90:11738-42. 
[48] Colciago A, Casati L, Negri-Cesi P, Celotti F. Learning and memory: Steroids and epigenetics. The Journal of steroid biochemistry and molecular biology. 2015;150:64-85.

[49] Shohamy D, Adcock RA. Dopamine and adaptive memory. Trends Cogn Sci. 2010;14:464-72.

[50] Buckland PR, Odonovan MC, Mcguffin P. Clozapine and Sulpiride up-Regulate Dopamine-D(3) Receptor Messenger-Rna Levels. Neuropharmacology. 1993;32:9017.

[51] Nakajima S, Gerretsen P, Takeuchi H, Caravaggio F, Chow T, Le Foll B, et al. The potential role of dopamine $\mathrm{D}(3)$ receptor neurotransmission in cognition. European neuropsychopharmacology : the journal of the European College of Neuropsychopharmacology. 2013;23:799-813.

[52] Marsden CA. Dopamine: the rewarding years. Br J Pharmacol. 2006;147 Suppl $1:$ S136-44.

[53] Watson DJG, Loiseau F, Ingallinesi M, Millan MJ, Marsden CA, Fone KCF. Selective Blockade of Dopamine D-3 Receptors Enhances while D-2 Receptor Antagonism Impairs Social Novelty Discrimination and Novel Object Recognition in Rats: A Key Role for the Prefrontal Cortex. Neuropsychopharmacol. 2012;37:770-86. [54] Powell SB, Paulus MP, Hartman DS, Godel T, Geyer MA. RO-10-5824 is a selective dopamine D4 receptor agonist that increases novel object exploration in C57 mice. Neuropharmacology. 2003;44:473-81. 
Fig. 1

A)

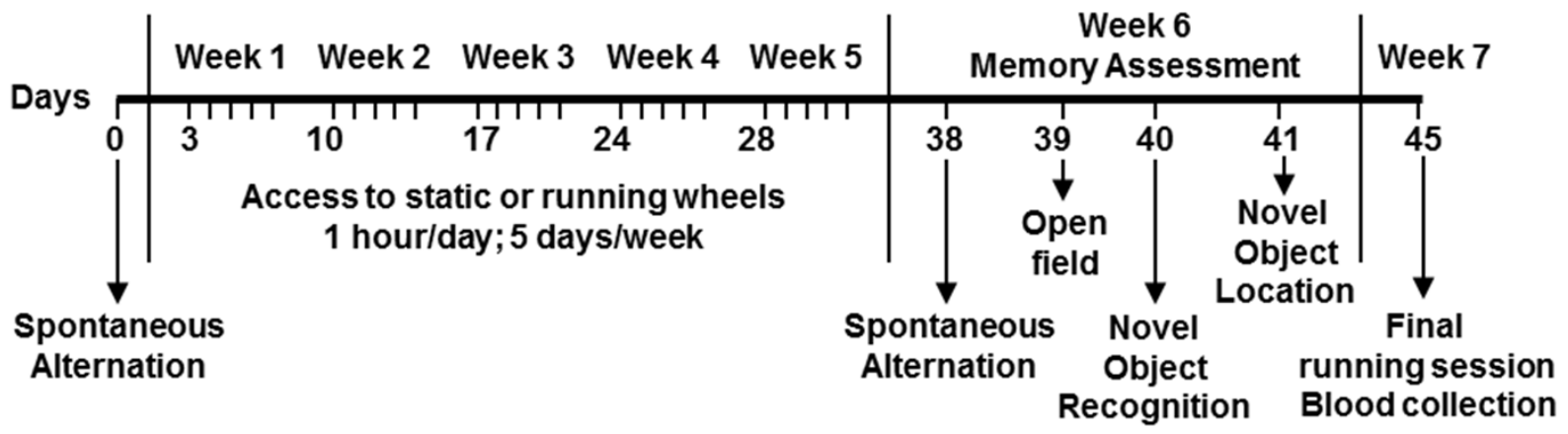

B)

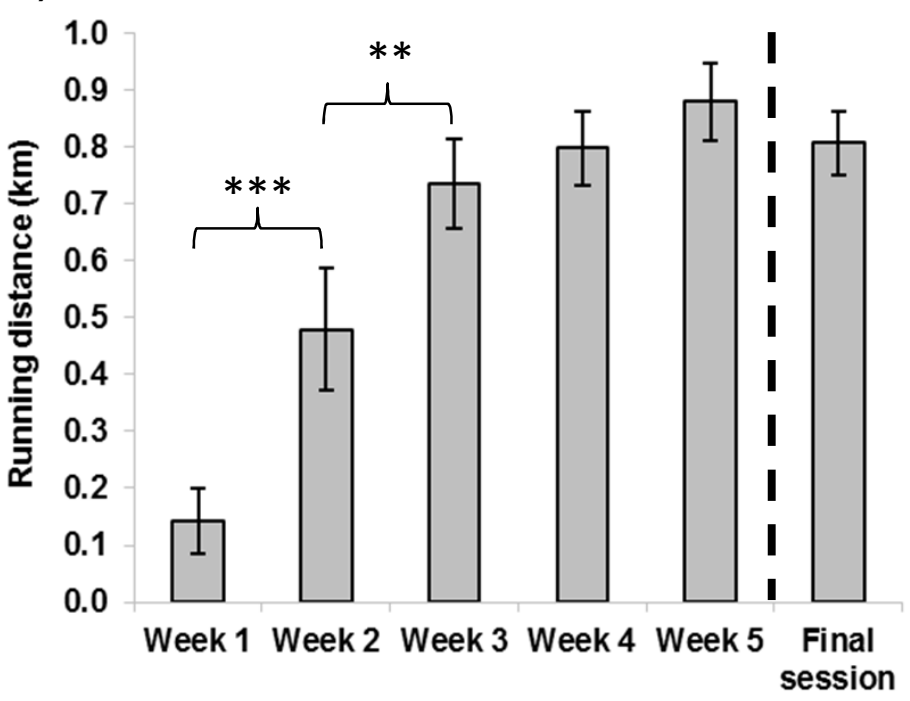

C)

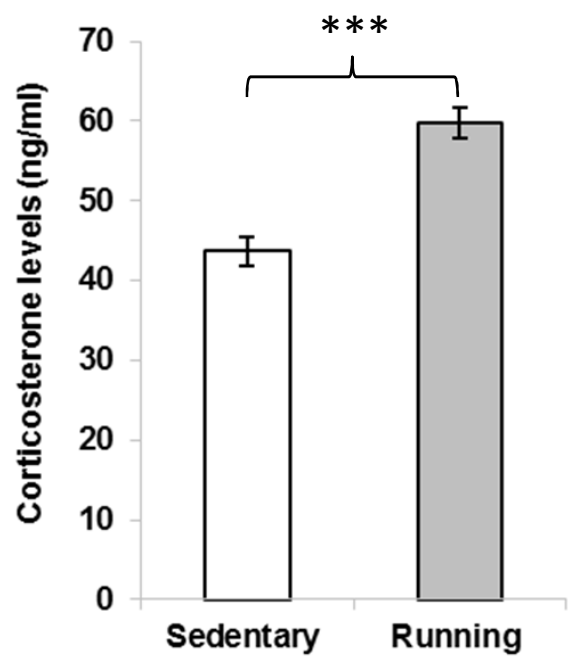


Fig. 2

A)

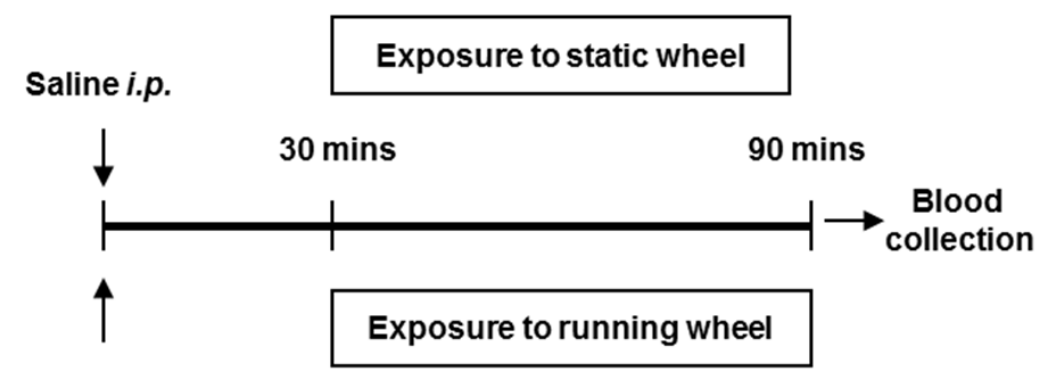

Saline or

Metyrapone

$35 \mathrm{mg} / \mathrm{kg}$, i.p.

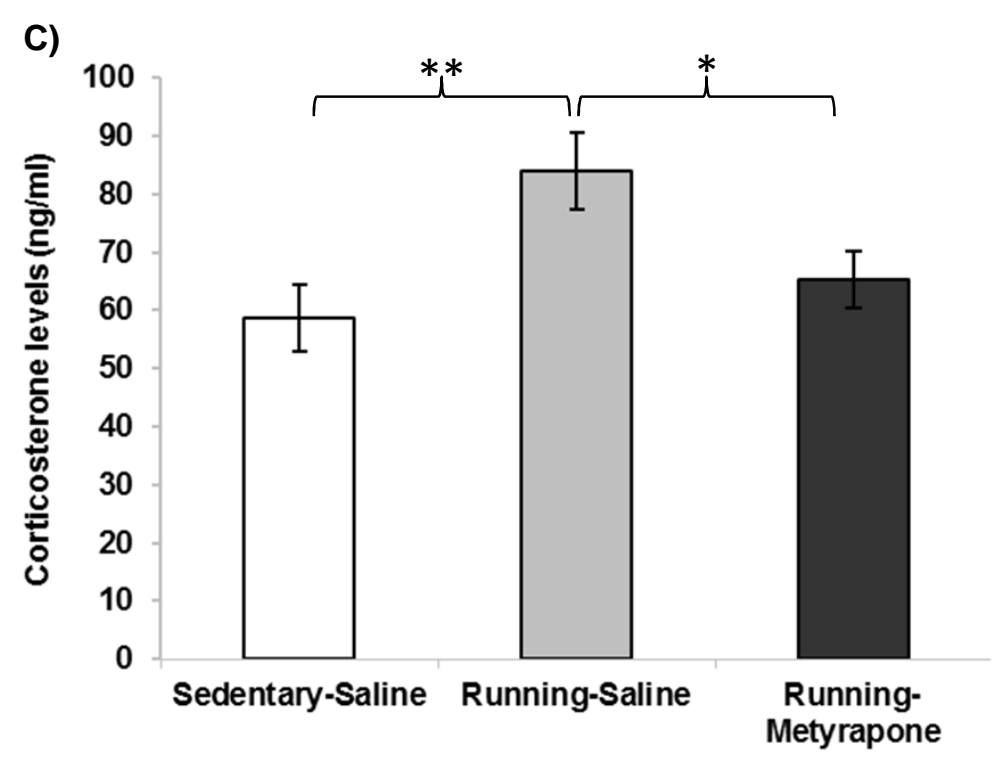

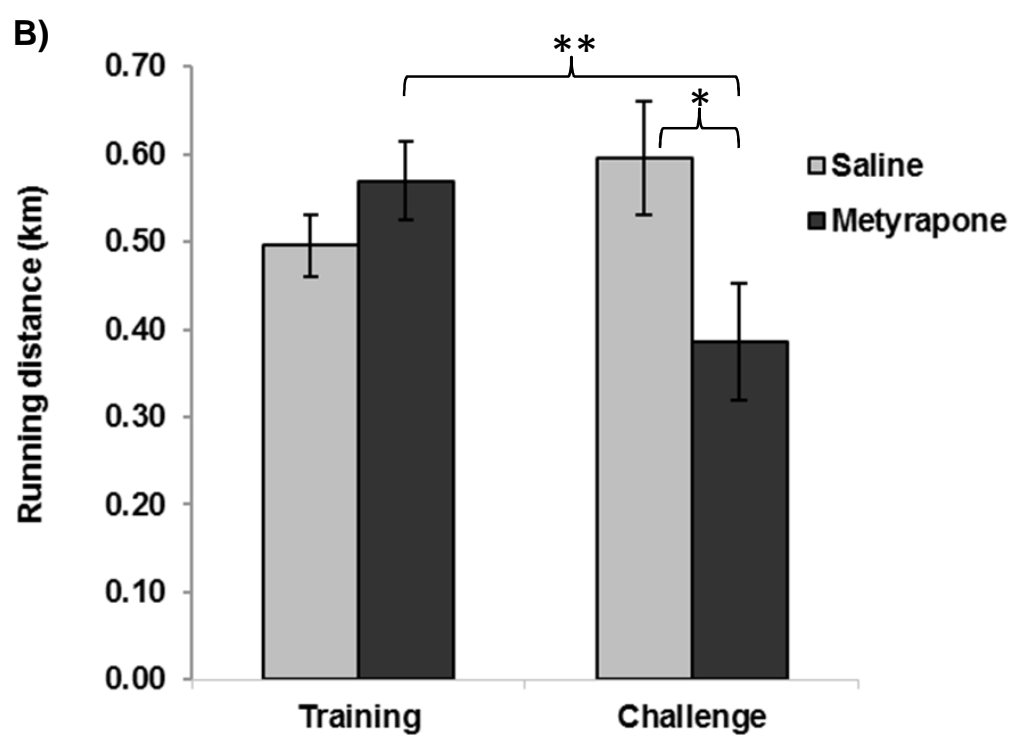

D)

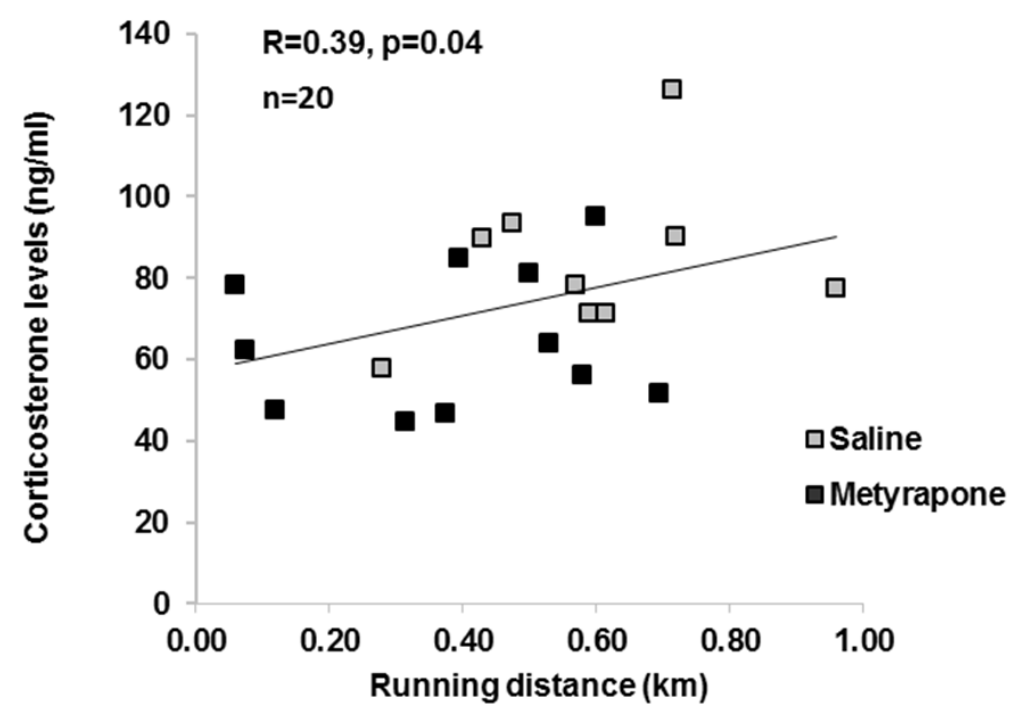


Fig. 3
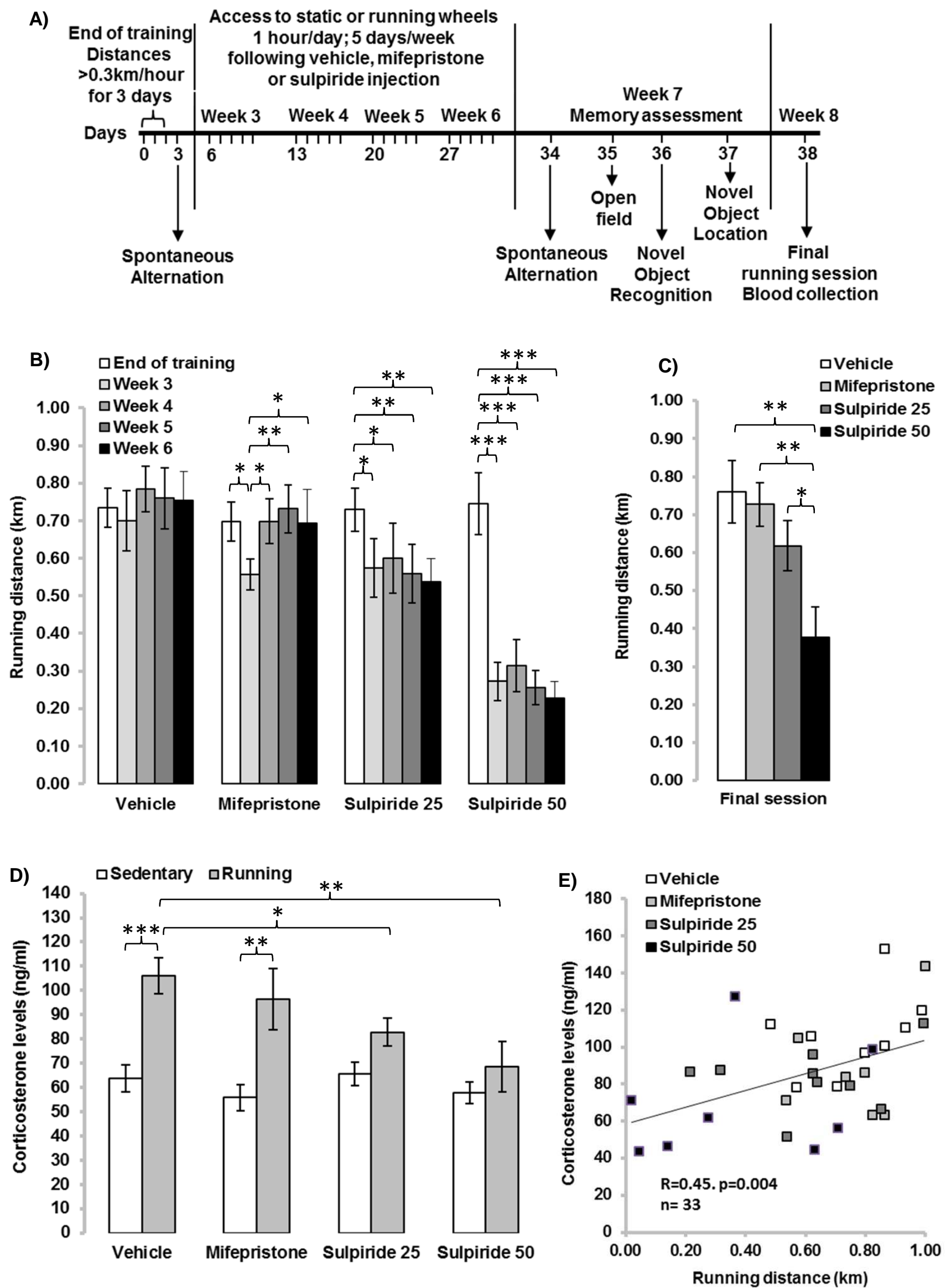
Fig. 4

A) Spatial alternation

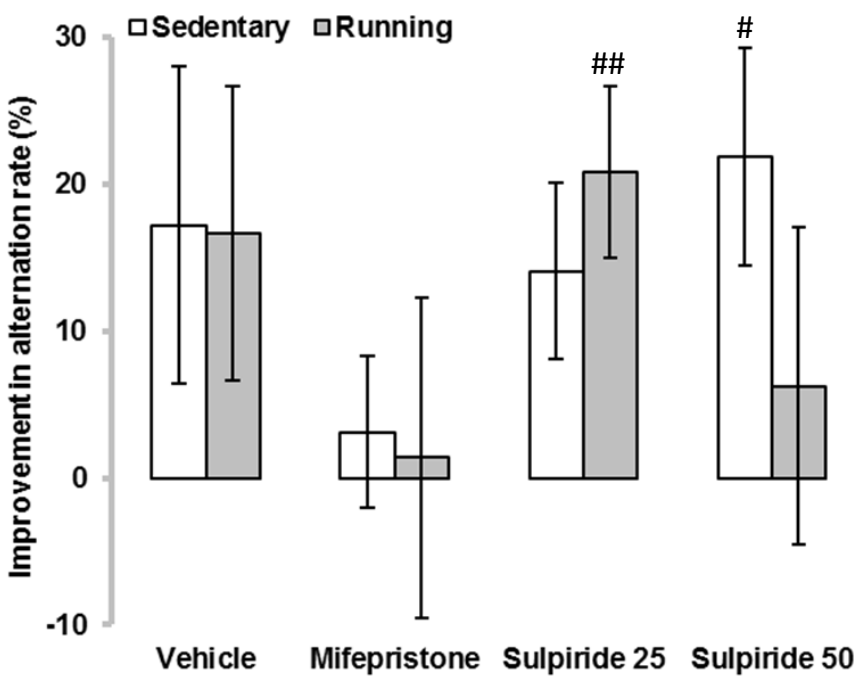

C) Object location

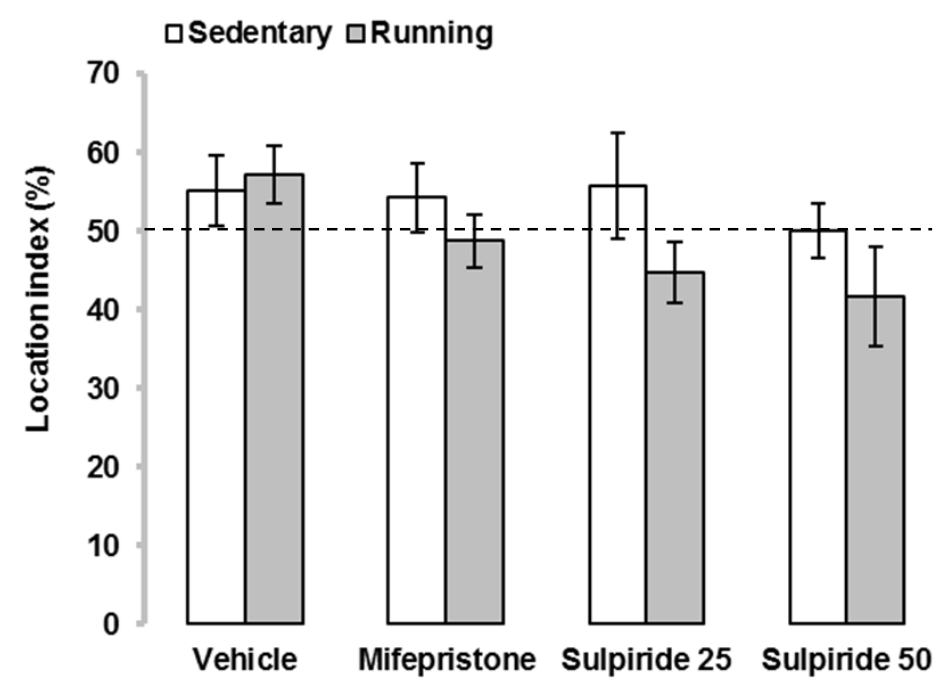

B) Object recognition

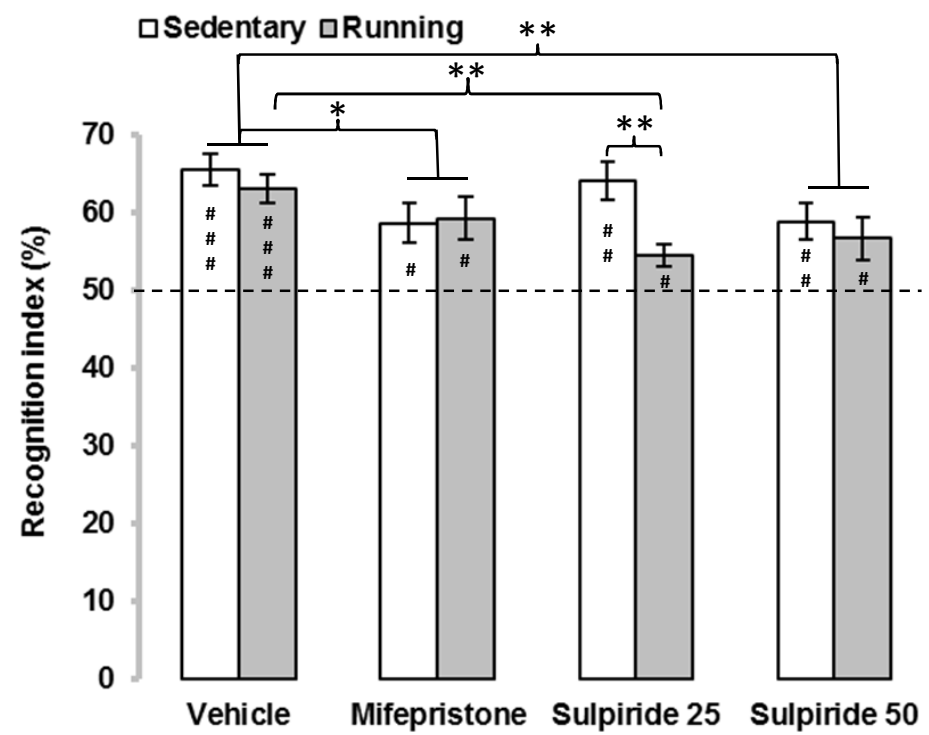

\section{D) Correlation}

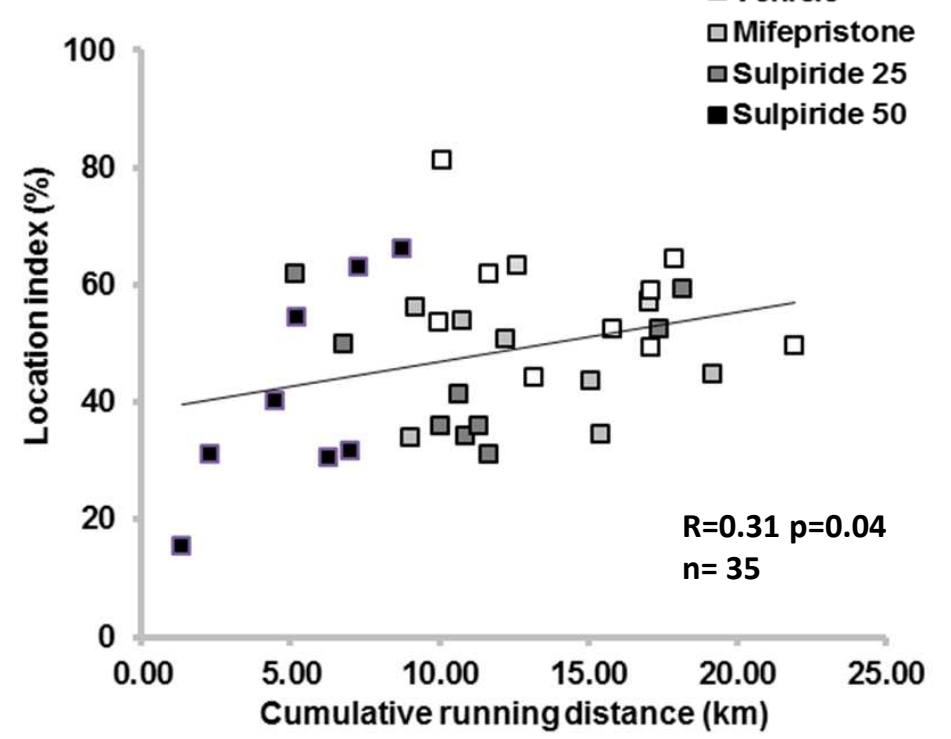


Fig. 5

A) Ambulation in open-field

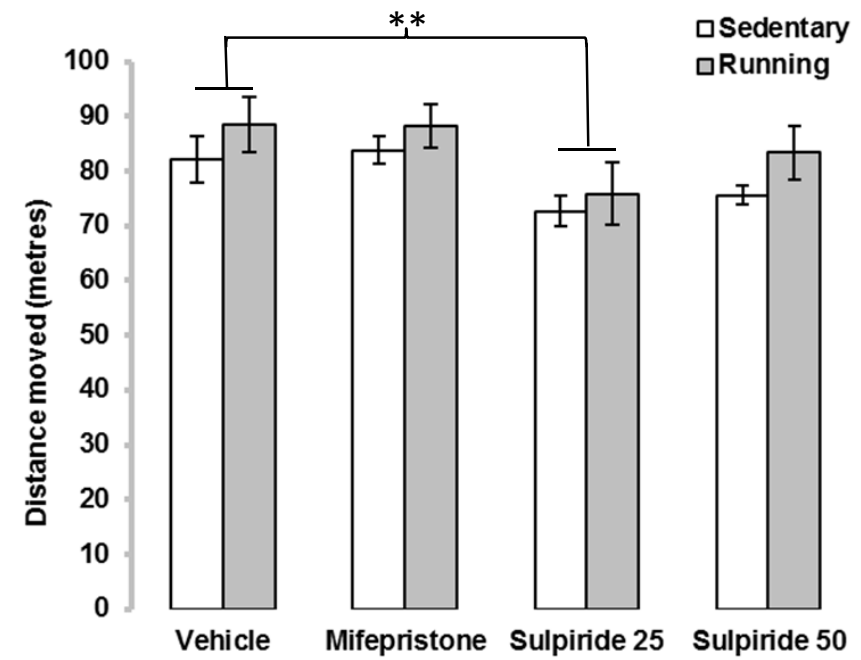

D) Object recognition

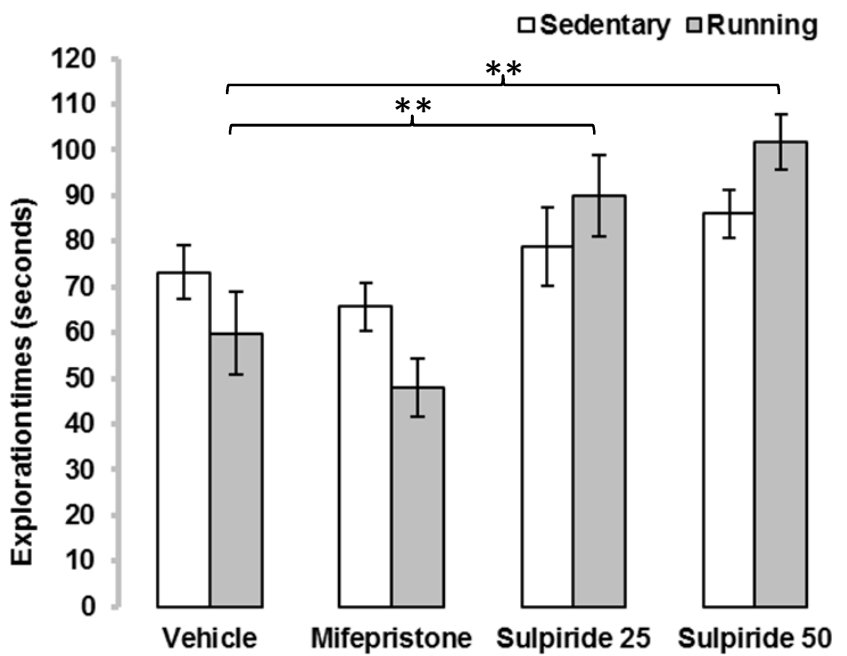

B) Anxiety-related behaviour in open-field

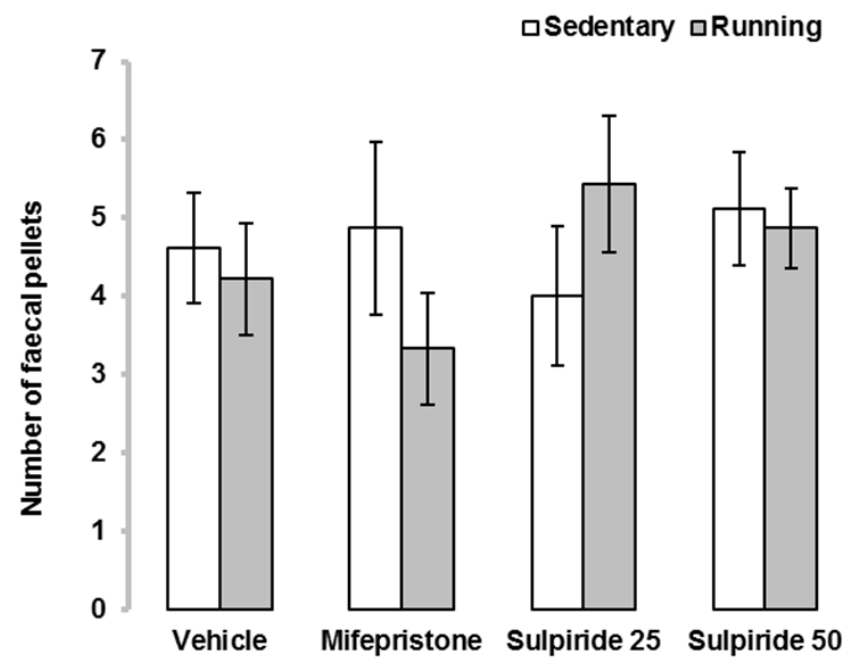

C) Correlation

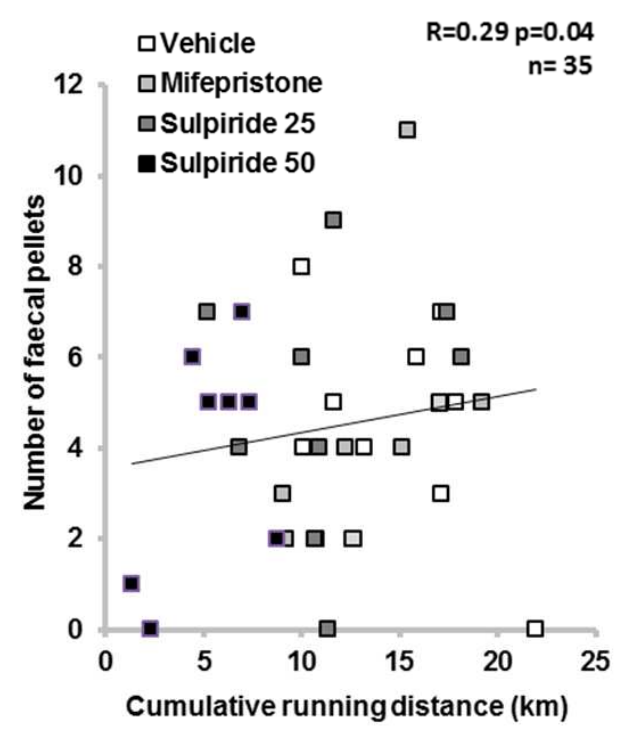

D) Object recognition correlation

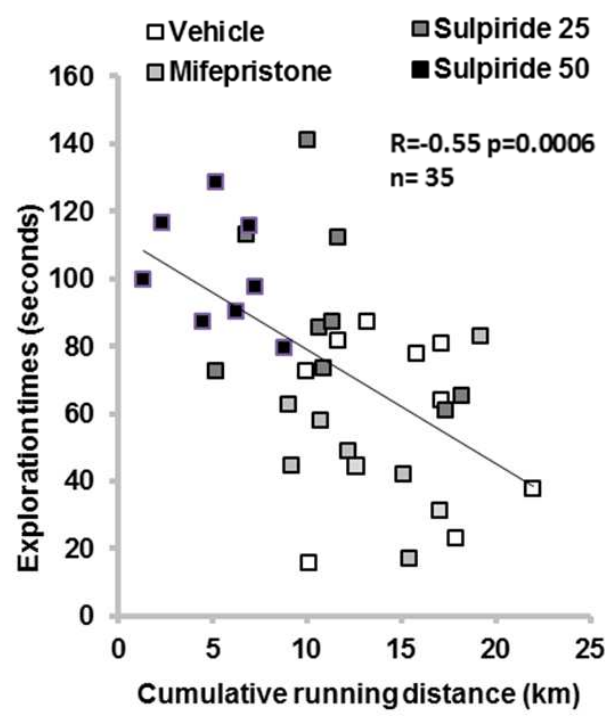

\section{F) Object location}

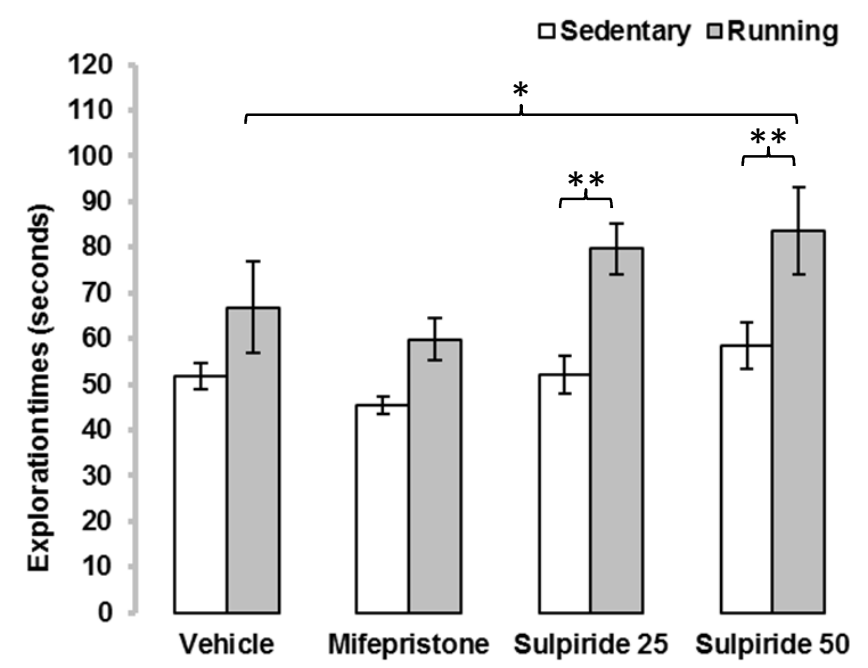


Table 1.

\begin{tabular}{|c|c|c|c|c|c|c|c|}
\hline & Exercise & Treatment & Time & $\begin{array}{l}\text { Exercise X } \\
\text { Treatment }\end{array}$ & $\begin{array}{l}\text { Exercise } X \\
\text { Time }\end{array}$ & $\begin{array}{c}\text { Treatment } X \\
\text { Time }\end{array}$ & $\begin{array}{c}\text { Exercise } X \\
\text { Treatment } X \\
\text { Time } \\
\end{array}$ \\
\hline \multicolumn{8}{|l|}{ Running distances } \\
\hline Sessions $(1-20)$ & N/A & $\begin{array}{c}F(3,60)=10.49 \\
\mathbf{p}<\mathbf{0 . 0 0 1}\end{array}$ & $\begin{array}{c}F(20,60)=5.00 \\
\mathbf{p}<\mathbf{0 . 0 0 1}\end{array}$ & N/A & N/A & $\begin{array}{l}F(3,60)=1.85 \\
\mathbf{p}=\mathbf{0 . 0 0 0 2}\end{array}$ & N/A \\
\hline Weeks 3-6 & N/A & $\begin{array}{c}F(3,31)=8.54 \\
\mathbf{p}=\mathbf{0 . 0 0 0 3}\end{array}$ & $\begin{array}{c}F(4,124)=11.56 \\
\mathbf{p}<\mathbf{0 . 0 0 1}\end{array}$ & N/A & N/A & $\begin{array}{c}\mathrm{F}(12,124)=5.61 \\
\mathbf{p}<\mathbf{0 . 0 0 1}\end{array}$ & N/A \\
\hline Final session (week 8)* & N/A & $\begin{array}{c}F(3,30)=4.52 \\
\mathbf{p}=\mathbf{0 . 0 0 9 9}\end{array}$ & N/A & N/A & N/A & N/A & N/A \\
\hline Corticosterone levels* & $\begin{array}{c}F(1,57)=25.98 \\
\mathbf{p}<\mathbf{0 . 0 0 0 1}\end{array}$ & $\begin{array}{c}F(3,57)=3.39 \\
\mathbf{p}=\mathbf{0 . 0 2 4}\end{array}$ & N/A & $\begin{array}{c}F(3,57)=1.96 \\
p=0.13\end{array}$ & N/A & N/A & N/A \\
\hline \multicolumn{8}{|l|}{ Spontaneous alternation } \\
\hline Alternation rate & $\begin{array}{c}F(1,59)=0.05 \\
p=0.82\end{array}$ & $\begin{array}{c}F(3,59)=0.56 \\
p=0.64\end{array}$ & $\begin{array}{c}F(1,59)=16.78 \\
\mathbf{p}<\mathbf{0 . 0 0 1}\end{array}$ & $\begin{array}{c}F(3,59)=0.25 \\
p=0.86\end{array}$ & $\begin{array}{c}F(1,59)=0.18 \\
p=0.67\end{array}$ & $\begin{array}{c}F(3,59)=1.36 \\
p=0.26\end{array}$ & $\begin{array}{c}F(3,59)=0.47 \\
p=0.65\end{array}$ \\
\hline $\begin{array}{r}\text { Improvement in alternation } \\
\text { rate }\end{array}$ & $\begin{array}{c}F(1,59)=0.18 \\
p=0.68\end{array}$ & $\begin{array}{c}F(3,59)=1.36 \\
p=0.26\end{array}$ & N/A & $\begin{array}{c}F(3,59)=0.56 \\
p=0.66\end{array}$ & N/A & N/A & N/A \\
\hline \multicolumn{8}{|l|}{ Open field } \\
\hline Distance moved & $\begin{array}{c}F(1,59)=3.35 \\
p=0.07\end{array}$ & $\begin{array}{c}F(3,59)=3.53 \\
\mathbf{p}=\mathbf{0 . 0 2 4}\end{array}$ & N/A & $\begin{array}{c}F(3,59)=0.12 \\
p=0.95\end{array}$ & N/A & N/A & N/A \\
\hline$\%$ distance in the centre & $\begin{array}{c}F(1,59)=0.90 \\
p=0.35\end{array}$ & $\begin{array}{c}F(3,59)=0.66 \\
p=0.58\end{array}$ & N/A & $\begin{array}{c}F(3,59)=0.01 \\
p=0.99\end{array}$ & N/A & N/A & N/A \\
\hline \multirow[t]{2}{*}{ Number of faecal pellets } & $\begin{array}{c}F(1,59)=0.11 \\
p=0.74\end{array}$ & $\begin{array}{c}F(3,59)=0.53 \\
p=0.66\end{array}$ & N/A & $\begin{array}{c}F(3,59)=1.21 \\
p=0.31\end{array}$ & N/A & N/A & N/A \\
\hline & Exercise & Treatment & Trial & $\begin{array}{l}\text { Exercise X } \\
\text { Treatment }\end{array}$ & $\begin{array}{l}\text { Exercise X } \\
\text { Trial }\end{array}$ & $\begin{array}{c}\text { Treatment } X \\
\text { Trial }\end{array}$ & $\begin{array}{c}\text { Exercise } X \\
\text { Treatment } X \\
\text { Trial } \\
\end{array}$ \\
\hline \multicolumn{8}{|l|}{ Object recognition } \\
\hline Exploration times & $\begin{array}{c}F(1,59)=0.05 \\
p=0.82\end{array}$ & $\begin{array}{c}F(3,59)=10.73 \\
\mathbf{p}<\mathbf{0 . 0 0 1}\end{array}$ & $\begin{array}{c}F(1,59)=0.60 \\
p=0.44\end{array}$ & $\begin{array}{c}F(3,59)=1.97 \\
p=0.13\end{array}$ & $\begin{array}{c}F(1,59)=0.11 \\
p=0.74\end{array}$ & $\begin{array}{c}F(3,59)=2.02 \\
p=0.12\end{array}$ & $\begin{array}{c}F(3,59)=1.09 \\
p=0.36\end{array}$ \\
\hline Recognition index & $\begin{array}{c}F(1,59)=4.42 \\
\mathbf{p}=\mathbf{0 . 0 4}\end{array}$ & $\begin{array}{c}F(3,59)=3.13 \\
\mathbf{p}=\mathbf{0 . 0 3 2}\end{array}$ & N/A & $\begin{array}{c}F(3,59)=1.75 \\
p=0.16\end{array}$ & N/A & N/A & N/A \\
\hline \multicolumn{8}{|l|}{ Object location } \\
\hline Exploration times & $\begin{array}{c}F(1,59)=20.24 \\
\mathbf{p}<\mathbf{0 . 0 0 1}\end{array}$ & $\begin{array}{c}F(3,59)=4.09 \\
\mathbf{p}=\mathbf{0 . 0 1}\end{array}$ & $\begin{array}{c}F(1,59)=16.78 \\
\mathbf{p}<\mathbf{0 . 0 0 1}\end{array}$ & $\begin{array}{c}F(3,59)=0.25 \\
p=0.86\end{array}$ & $\begin{array}{c}F(1,59)=5.89 \\
\mathbf{p}=\mathbf{0 . 0 2}\end{array}$ & $\begin{array}{c}F(3,59)=0.69 \\
p=0.56\end{array}$ & $\begin{array}{c}F(3,59)=0.82 \\
p=0.49\end{array}$ \\
\hline Location index & $\begin{array}{c}F(1,59)=3.00 \\
p=0.09\end{array}$ & $\begin{array}{c}F(3,59)=1.78 \\
p=0.16\end{array}$ & N/A & $\begin{array}{c}F(3,59)=0.77 \\
p=0.52\end{array}$ & N/A & N/A & N/A \\
\hline
\end{tabular}

* One mifepristone-treated mouse was excluded due to issues with the injection. N/A: non applicable. 
- Corticosterone synthesis contributes to voluntary wheel running performance

- Effects of corticosterone on motivation to exercise are not mediated by GRs

- Blockade of dopamine D2/D3 receptors dose-dependently reduces running activity

- Reducing motivation to exercise is not sufficient to alter behaviour in C57BL6 mice 
A)
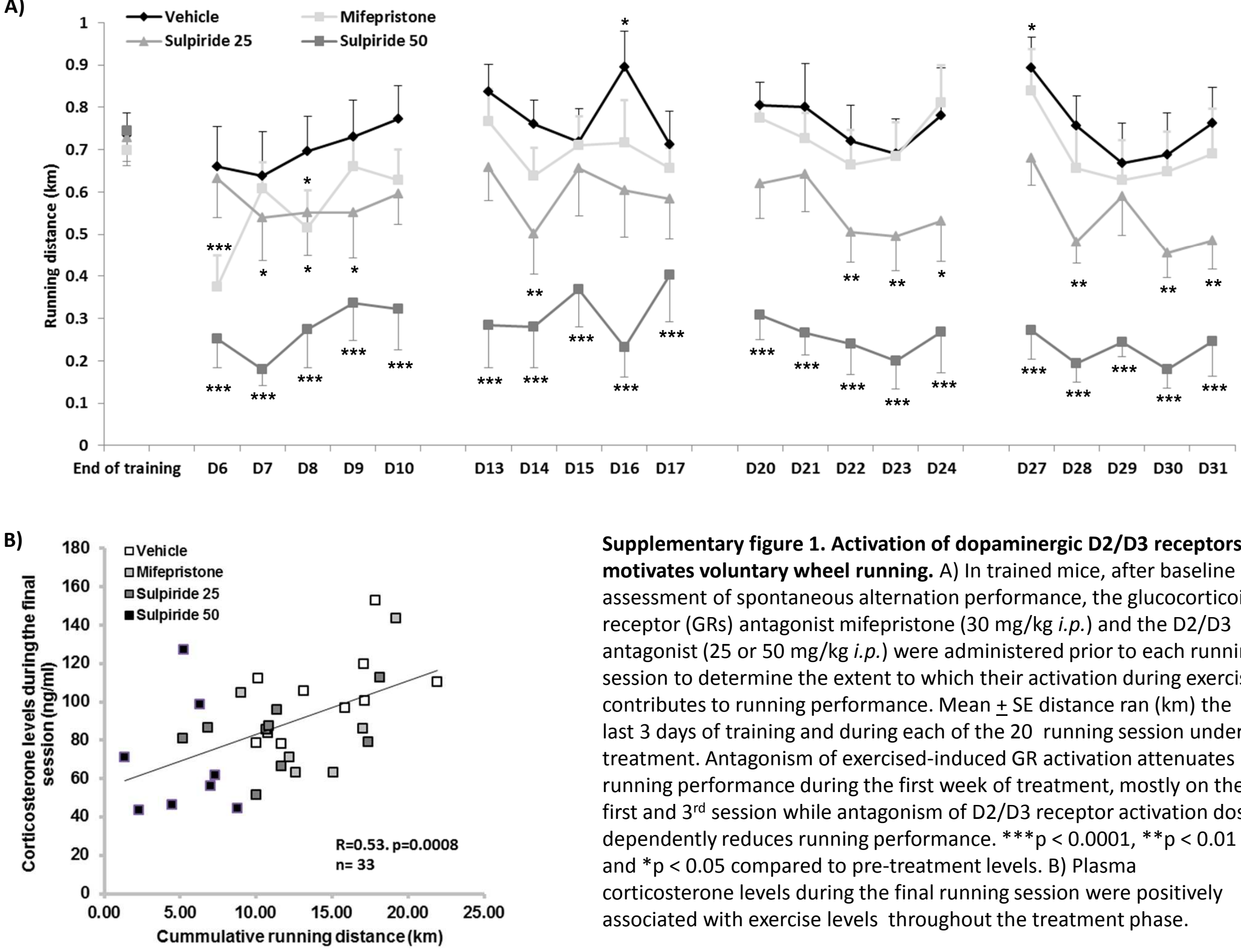

Supplementary figure 1. Activation of dopaminergic D2/D3 receptors motivates voluntary wheel running. A) In trained mice, after baseline assessment of spontaneous alternation performance, the glucocorticoid receptor (GRs) antagonist mifepristone (30 $\mathrm{mg} / \mathrm{kg}$ i.p.) and the D2/D3 antagonist ( 25 or $50 \mathrm{mg} / \mathrm{kg}$ i.p.) were administered prior to each running session to determine the extent to which their activation during exercise contributes to running performance. Mean $+\mathrm{SE}$ distance ran $(\mathrm{km})$ the last 3 days of training and during each of the 20 running session under treatment. Antagonism of exercised-induced GR activation attenuates running performance during the first week of treatment, mostly on the first and $3^{\text {rd }}$ session while antagonism of D2/D3 receptor activation dosedependently reduces running performance. ${ }^{* * *} p<0.0001, * * p<0.01$ and $* p<0.05$ compared to pre-treatment levels. B) Plasma corticosterone levels during the final running session were positively associated with exercise levels throughout the treatment phase. 
Supplementary Table 1 . Mean \pm SE body weight and performance for all behavioural variables.

\begin{tabular}{|c|c|c|}
\hline & Sedentary & Running \\
\hline \multicolumn{3}{|l|}{ Body Weight (grams) } \\
\hline Day 0 & $24.29 \pm 0.80$ & $25.18 \pm 0.26$ \\
\hline Day 49 & $26.84 \pm 0.54$ & $26.94 \pm 0.51$ \\
\hline Weight gain & $2.55 \pm 0.42$ & $1.76 \pm 0.37$ \\
\hline \multicolumn{3}{|l|}{ Spontaneous Alternation Rate (\%) } \\
\hline Day 0 & $63.75 \pm 6.57$ & $62.50 \pm 6.18$ \\
\hline Day 38 & $75.00 \pm 6.45$ & $55.00 \pm 8.58$ \\
\hline \multicolumn{3}{|l|}{ Open Field } \\
\hline Distance travelled (metres) & $90.97 \pm 3.22$ & $96.17 \pm 4.84$ \\
\hline$\%$ distanced travelled in the centre & $11.75 \pm 0.53$ & $10.84 \pm 0.38$ \\
\hline$\%$ time spent in the centre & $9.31 \pm 0.84$ & $8.02 \pm 0.71$ \\
\hline Number of faecal pellets & $6.80 \pm 0.61$ & $5.90 \pm 0.86$ \\
\hline \multicolumn{3}{|l|}{ Novel Object Recognition } \\
\hline Exploration Times Trial 1 (seconds) & $52.20 \pm 4.90$ & $64.00 \pm 9.32$ \\
\hline Exploration Times Trial 2 (seconds) & $48.65 \pm 4.54$ & $65.75 \pm 9.34$ \\
\hline Recognition Index (\%) & $57.60 \pm 3.02 *$ & $62.95 \pm 2.18 * *$ \\
\hline \multicolumn{3}{|l|}{ Novel Object Location } \\
\hline Exploration Times Trial 1 (seconds) & $51.45 \pm 5.93$ & $54.65 \pm 8.23$ \\
\hline Exploration Times Trial 2 (seconds) & $45.75 \pm 2.86$ & $56.45 \pm 7.66$ \\
\hline Location Index (\%) & $53.35 \pm 3.27$ & $56.85 \pm 3.49$ \\
\hline
\end{tabular}

$* \mathrm{p}<0.5, * * \mathrm{p}<0.01$ compared to chance $50 \%$ 
Supplementary Table 2. Behavioural effects of enrichment and injection. Data are presented as means $\pm \mathrm{SE}$.

\begin{tabular}{|c|c|c|c|c|}
\hline & $\begin{array}{l}\text { Vehicle - } \\
\text { No wheel }\end{array}$ & $\begin{array}{c}\text { Vehicle - } \\
\text { Sedentary }\end{array}$ & $\begin{array}{l}\text { Vehicle - } \\
\text { Running }\end{array}$ & $\begin{array}{l}\text { Non injected - } \\
\text { Running }\end{array}$ \\
\hline \multicolumn{5}{|l|}{ Running distances (km) } \\
\hline Training & & & $0.73 \pm 0.05$ & $0.60 \pm 0.02$ \\
\hline Week 1 & & & $0.70 \pm 0.08$ & $0.67 \pm 0.08$ \\
\hline Week 2 & & & $0.78 \pm 0.06$ & $0.78 \pm 0.12$ \\
\hline Week 3 & & & $0.76 \pm 0.08$ & $0.77 \pm 0.10$ \\
\hline Week 4 & & & $0.75 \pm 0.08$ & $0.77 \pm 0.10$ \\
\hline Final Session & & & $0.76 \pm 0.06$ & $0.65 \pm 0.08$ \\
\hline Corticosterone levels (ng/ml) & $60.24 \pm 4.94$ & $63.80 \pm 5.66$ & $106.04 \pm 7.52$ & $100.01 \pm 8.08$ \\
\hline \multicolumn{5}{|l|}{ Alternation Rate (\%) } \\
\hline Before treatment (Day 3) & $43.75 \pm 9.45$ & $45.31 \pm 7.45$ & $45.83 \pm 8.84$ & $45.31 \pm 11.56$ \\
\hline Day 34 & $60.94 \pm 7.26$ & $62.50 \pm 11.08$ & $62.50 \pm 6.59$ & $60.94 \pm 6.44$ \\
\hline \multicolumn{5}{|l|}{ Open Field } \\
\hline Distance travelled (metres) & $82.06 \pm 5.33$ & $82.07 \pm 4.20$ & $88.50 \pm 4.94$ & $88.72 \pm 4.65$ \\
\hline$\%$ distanced travelled in the centre & $13.38 \pm 0.97$ & $14.88 \pm 0.89$ & $15.54 \pm 0.98$ & $15.36 \pm 0.72$ \\
\hline$\%$ time spent in the centre & $10.70 \pm 1.21$ & $11.96 \pm 0.88$ & $12.56 \pm 1.40$ & $11.88 \pm 0.84$ \\
\hline Number of faecal pellets & $5.00 \pm 0.46$ & $4.62 \pm 0.70$ & $4.22 \pm 0.72$ & $5.62 \pm 1.10$ \\
\hline \multicolumn{5}{|l|}{ Novel Object Recognition } \\
\hline Exploration Times Trial 1 (seconds) & $34.94 \pm 7.13$ & $73.25 \pm 5.83^{\mathrm{a}}$ & $59.89 \pm 9.09$ & $84.25 \pm 7.30$ \\
\hline Exploration Times Trial 2 (seconds) & $42.75 \pm 6.33$ & $68.62+3.93^{\mathrm{a}}$ & $62.67 \pm 8.59$ & $69.50 \pm 7.54$ \\
\hline Recognition Index (\%) & $62.21 \pm 4.17^{*}$ & $65.54 \pm 1.99 *$ & $62.98 \pm 1.82 *$ & $59.54 \pm 3.31^{*}$ \\
\hline \multicolumn{5}{|l|}{ Novel Object Location } \\
\hline Exploration Times Trial 1 (seconds) & $39.00 \pm 7.22$ & $51.75 \pm 8.23$ & $66.89 \pm 3.92$ & $74.75 \pm 10.05$ \\
\hline Exploration Times Trial 2 (seconds) & $45.56 \pm 6.26$ & $55.56 \pm 7.66$ & $66.44 \pm 5.97$ & $63.81 \pm 5.80$ \\
\hline Location Index (\%) & $65.83 \pm 4.00 *$ & $55.08 \pm 4.43$ & $57.23 \pm 3.69$ & $59.89 \pm 3.44 *$ \\
\hline
\end{tabular}

${ }^{\mathrm{a}}, \mathrm{p}<0.01$ compared to vehicle-no wheel

$*, p<0.05$ compared to chance levels $(50 \%)$ 
Supplementary table 3. Mean \pm SE body weight and behavioural performance for variables not affected by exercise or treatment.

\begin{tabular}{|c|c|c|c|c|c|c|c|c|}
\hline & \multicolumn{2}{|c|}{ Vehicle } & \multicolumn{2}{|c|}{ Mifepristone } & \multicolumn{2}{|c|}{ Sulpiride 25mg/kg } & \multicolumn{2}{|c|}{ Sulpiride 50mg/kg } \\
\hline & Sedentary & Running & Sedentary & Running & Sedentary & Running & Sedentary & Running \\
\hline \multicolumn{9}{|l|}{ Body weight } \\
\hline Prior to Training & $23.50 \pm 0.88$ & $23.45 \pm 0.56$ & $22.65 \pm 0.54$ & $24.49 \pm 0.37$ & $23.62 \pm 0.47$ & $23.04 \pm 0.83$ & $22.91 \pm 0.88$ & $23.82 \pm 0.54$ \\
\hline Day 38 & $25.50 \pm 0.64$ & $26.18 \pm 0.23$ & $24.00 \pm 0.45$ & $24.58 \pm 0.45$ & $26.34 \pm 0.52$ & $26.55 \pm 0.29$ & $25.96 \pm 0.81$ & $26.17 \pm 0.59$ \\
\hline Weight gain & $2.00 \pm 0.48$ & $2.72 \pm 0.49$ & $1.35 \pm 0.36$ & $0.09 \pm 0.44$ & $2.71 \pm 0.49$ & $3.51 \pm 0.67$ & $3.05 \pm 0.42$ & $2.35 \pm 0.49$ \\
\hline \multicolumn{9}{|l|}{ Spontaneous alternation } \\
\hline Day 3 alternation rate $(\%)$ & $45.31 \pm 7.45$ & $45.83 \pm 8.84$ & $45.31 \pm 10.91$ & $47.22 \pm 10.16$ & $45.31 \pm 7.81$ & $50.00 \pm 8.33$ & $45.31 \pm 9.13$ & $48.44 \pm 10.14$ \\
\hline Day 34 alternation rate $(\%)$ & $62.50 \pm 11.08$ & $62.50 \pm 6.59$ & $48.43 \pm 9.86$ & $48.61 \pm 7.92$ & $59.37 \pm 4.57$ & $70.83^{*} \pm 5.59$ & $67.19 * \pm 6.22$ & $54.69 \pm 10.28$ \\
\hline \multicolumn{9}{|l|}{ Anxiety-related behaviour in open-field } \\
\hline$\%$ distance in the centre & $14.88 \pm 0.89$ & $15.54 \pm 0.98$ & $14.66 \pm 0.97$ & $15.17 \pm 1.07$ & $14.60 \pm 1.12$ & $15.40 \pm 0.99$ & $15.82 \pm 0.77$ & $16.51 \pm 1.04$ \\
\hline Number of faecal pellets & $4.62 \pm 0.70$ & $4.22 \pm 0.72$ & $4.87 \pm 1.11$ & $3.33 \pm 0.71$ & $4.00 \pm 0.89$ & $5.44 \pm 0.87$ & $5.12 \pm 0.72$ & $4.87 \pm 0.51$ \\
\hline \multicolumn{7}{|l|}{ Object exploration times } & \multicolumn{2}{|c|}{$\#$ \# } \\
\hline Object location (recognition trial) & $68.62 \pm 3.93$ & $62.66 \pm 8.59$ & $66.62 \pm 6.78$ & $61.33 \pm 6.34$ & $72.62 \pm 4.89$ & $80.39 \pm 7.70$ & $84.69 \pm 5.48$ & $89.50 \pm 7.08$ \\
\hline Object location (retention trial) & $55.56 \pm 3.92$ & $66.44 \pm 5.97$ & $49.44 \pm 2.07$ & $60.44 \pm 2.20$ & $55.06 \pm 5.82$ & $67.17 \pm 6.40$ & $65.75 \pm 4.42$ & $72.62 \pm 5.73$ \\
\hline
\end{tabular}

${ }^{*}, \mathrm{p}<0.05$ compared to chance levels $(50 \%)$

\#\#, $\mathrm{p}<0.01$ compared to vehicle-treated groups 